\title{
The Impact of Health Care Reform on Hospital and Preventive Care: Evidence from Massachusetts ${ }^{\star}$
}

\author{
Jonathan T. Kolstad ${ }^{\mathrm{a}}$ and Amanda E. Kowalski ${ }^{\mathrm{b},{ }^{*}}$ \\ aThe Wharton School, University of Pennsylvania and NBER \\ ${ }^{b}$ Department of Economics, Yale University and NBER
}

\section{Abstract}

In April 2006, Massachusetts passed legislation aimed at achieving near-universal health insurance coverage. The key features of this legislation were a model for national health reform, passed in March 2010. The reform gives us a novel opportunity to examine the impact of expansion to near-universal coverage state-wide. Among hospital discharges in Massachusetts, we find that the reform decreased uninsurance by $36 \%$ relative to its initial level and to other states. Reform affected utilization by decreasing length of stay, the number of inpatient admissions originating from the emergency room, and preventable admissions. At the same time, hospital cost growth did not increase.

\section{Keywords}

health; health care; health reform; insurance; hospitals; Massachusetts; preventive care

\section{Introduction}

In April 2006, the state of Massachusetts passed legislation aimed at achieving nearuniversal health insurance coverage. This legislation has been considered by many to be a model for the national health reform legislation passed in March 2010. In light of both reforms, it is of great policy importance to understand the impact of a growth in coverage to near-universal levels, unprecedented in the United States. In theory, insurance coverage could increase or decrease the intensity and cost of health care, depending on the underlying demand for care and its impact on health care delivery. Which effect dominates in practice is an empirical question.

Although previous researchers have studied the impact of expansions in health insurance coverage, these studies have focused on specific subpopulations - the indigent, children, and the elderly (see e.g. Currie and Gruber (1996); Finkelstein (2007); Card et al. (2008);

Finkelstein et al. (2012)). The Massachusetts reform gives us a novel opportunity to examine the impact of a policy that achieved near-universal health insurance coverage among the entire state population. Furthermore, the magnitude of the expansion in coverage after the

\footnotetext{
(c) 2012 Published by Elsevier B.V.

"Corresponding author. Mailing address: Department of Economics, Yale University, Box 208264, New Haven, CT 06520-8264, United States. amanda.kowalski@yale.edu. Telephone: +1-202-670-7631. Fax: +1-203-432-6323.

Publisher's Disclaimer: This is a PDF file of an unedited manuscript that has been accepted for publication. As a service to our customers we are providing this early version of the manuscript. The manuscript will undergo copyediting, typesetting, and review of the resulting proof before it is published in its final citable form. Please note that during the production process errors may be discovered which could affect the content, and all legal disclaimers that apply to the journal pertain.
} 
Massachusetts reform is similar to the predicted magnitude of the coverage expansion in the national reform. In this paper, we are the first to use hospital data to examine the impact of this legislation on insurance coverage, patient outcomes, and utilization patterns in Massachusetts. We use a difference-in-differences strategy that compares Massachusetts after the reform to Massachusetts before the reform and to other states.

The first question we address is whether the Massachusetts reform resulted in reductions in uninsurance. We consider overall changes in coverage as well as changes in the composition of types of coverage among the entire state population and the population who were hospitalized. One potential impact of expansions in publicly subsidized coverage is to crowd-out private insurance (Cutler and Gruber (1996)). The impact of the reform on the composition of coverage allows us to consider crowd-out in the population as a whole as well as among those in the inpatient setting.

After estimating changes in the presence and composition of coverage, we turn to the impact of the reform on hospital and preventive care. We first study the intensity of care provided. Because health insurance lowers the price of health care services to consumers, a large-scale expansion in coverage has the potential to increase demand for health care services, the intensity of treatment, and cost. Potentially magnifying this effect are general equilibrium shifts in the way care is supplied due to the large magnitude of the expansion (Finkelstein 2007)). Countervailing this effect is the monopsonistic role of insurance plans in setting prices and quantities for hospital services. To the extent that health reform altered the negotiating position of insurers vis a vis hospitals, expansions in coverage could actually reduce supply of services, intensity of treatment, or costs. Furthermore, the existence of insurance itself can also alter the provision of care in the hospital directly (e.g. substitution towards services that are reimbursed). Without coverage, patients could face barriers to receiving follow up treatment (typically dispensed in an outpatient setting or as drug prescriptions); potentially reducing the efficacy of the inpatient care they receive or altering the length of time they stay in the hospital. Achieving near-universal insurance could alter length of stay and other measures of services intensity though physical limits on the number of beds in the hospital, efforts to increase throughput in response to changes in profitability, or changes in care provided when physicians face a pool of patients with more homogeneous coverage (Glied and Zivin (2002)). Given these competing hypotheses, expanded insurance coverage could raise or lower the intensity of care provided.

In addition to changes in the production process within a hospital, we are interested in the impact of insurance coverage on how patients enter the health care system and access preventive care. We first examine changes in the use of the emergency room (ER) as a point of entry for inpatient care. Because hospitals must provide at least some care, regardless of insurance status, the ER is a potentially important point of access to hospital care for the uninsured. ${ }^{1}$ When the ER is the primary point of entry into the hospital, changes in admissions from the ER can impact welfare for a variety of reasons. First, the cost of treating patients in the ER is likely higher than the cost of treating the same patient in another setting. Second, the emergency room is designed to treat acute health events. If the ER is a patient's primary point of care, then he might not receive preventive care that could mitigate future severe and costly health events. To the extent that uninsurance led people to use the ER as a point of entry for treatment that they otherwise would have sought through another channel, we expect to see a decline in the number of inpatient admissions originating in the ER.

\footnotetext{
${ }^{1}$ Under the Emergency Medical Treatment and Labor Act (EMTALA), hospitals must provide stabilizing care and examination to people who arrive in the ER for an emergency condition without considering whether a person is insured or their ability to pay.
} 
We also study the impact of insurance on access to care outside of the inpatient setting. Using a methodology developed by the Agency for Health-care Research and Quality (AHRQ), we are able to study preventive care in an outpatient setting using inpatient data. We identify inpatient admissions that should not occur in the presence of sufficient preventive care. If the reform facilitated increased preventive care, then we expect a reduction in the number of inpatient admissions meeting these criteria. These measures also indirectly measure health in the form of averted hospitalizations. We augment this analysis with data on direct measures of access to and use of outpatient and preventive care.

Finally, we turn to the impact of the reform on the cost of hospital care. We examine hospital-level measures of operating costs (e.g. overhead, salaries, and equipment) that include both fixed and variable costs. This allows us to jointly measure the direct effect of insurance on cost - the relative effect of changing the out of pocket price - as well as the potential for quality competition at the hospital level. In the latter case, hospitals facing consumers who are relatively less price elastic (or more quality elastic) increase use of costly services and may also increase use of variable inputs as well as investments in large capital projects in order to attract price-insensitive customers (Dranove and Satterthwaite 1992)). In the extreme, large expansions in coverage might lead to a so called "medical arms race," in which hospitals make investments in large capital projects to attract customers and are subsequently able to increase demand to cover these fixed costs (Robinson and Luft (1987)). The impact of all of these effects would be increased hospital costs as coverage approaches near-universal levels.

Our analysis relies on three main data sets. To examine the impact on coverage in Massachusetts as a whole, we analyze data from the Current Population Survey (CPS). To examine coverage among the hospitalized population, health care utilization, and preventive care, we analyze the universe of hospital discharges from a nationally-representative sample of approximately 20 percent of hospitals in the United States from the Healthcare Cost and Utilization Project (HCUP) National Inpatient Sample (NIS). In addition, we use the Behavioral Risk Factor Surveillance System (BRFSS) data to augment our study of access and preventive care.

We find a variety of results pointing to an impact of the Massachusetts reform on insurance coverage, hospital, and preventive care. First, we find a significant reduction in uninsurance both in the general population and among those who are hospitalized. In the population as a whole, we find that uninsurance declined by roughly 6 percentage points, or by about $50 \%$ of its initial level. This decline primarily came through increased coverage by employersponsored health insurance (ESHI), which accounted for nearly half the change, and secondarily through Medicaid and newly subsidized coverage available through the Massachusetts connector. Turning to hospital and preventive care, we find that length of stay in the hospital fell significantly, particularly for long hospital stays. We also find a significant reduction emergency room utilization that resulted in an inpatient admission. Admissions originating in the ER declined by 5.2\%. The impact on ER utilization was largest in poorer geographic areas. Our results provide some mixed evidence for a decline in preventable admissions to the hospital. Without including covariates that capture patient severity, we find limited evidence that the reform reduced preventable admissions. However, in a specification that controls for patient severity, we find clear evidence that preventable admissions were reduced. Finally, we find little evidence that the Massachusetts reform affected hospital cost growth. Massachusetts hospital costs appear to have been growing faster than the remainder of the country prior to reform and to have continued on the same trajectory. 
In the next section, we describe the elements of the reform and its implementation, as well as the limited existing research on its impact. In the third section, we describe the data. In the fourth section, we present the difference-in-differences results for the impact of the reform on insurance coverage and hospital and preventive care. In the fifth section, we discuss the implications of our findings for national reform. In the sixth section, we conclude and discuss our continuing work in this area.

\section{Description of the Reform}

The recent Massachusetts health insurance legislation, Chapter 58, included several features, the most salient of which was a mandate for individuals to obtain health insurance coverage or pay a tax penalty. All individuals were required to obtain coverage, with the exception of individuals with religious objections and individuals whose incomes were too high to qualify for state health insurance subsidies but too low for health insurance to be "affordable," as determined by the Massachusetts Health Insurance Connector Authority. For a broad summary of the reform, see McDonough et al. (2006); for details on the implementation of the reform see The Massachusetts Health Insurance Connector Authority (2008).

The reform also extended free and subsidized health insurance to low income populations in two forms: expansions in the existing Medicaid program (called "MassHealth" in Massachusetts), and the launch of a new program called CommCare. First, as part of the Medicaid expansion, the reform expanded Medicaid eligibility for children to 300 percent of poverty, and it restored benefits to special populations who had lost coverage during the 2002-2003 fiscal crisis, such as the long-term unemployed. The reform also facilitated outreach efforts to Medicaid-eligible individuals and families. Implementation of the reform was staggered, and Medicaid changes were among the first to take effect. According to one source, "Because enrollment caps were removed from one Medicaid program and income eligibility was raised for two others, tens of thousands of the uninsured were newly enrolled just ten weeks after the law was signed" (Kingsdale (2009), page w591).

Second, the reform extended free and subsidized coverage through a new program called CommCare. CommCare offered free coverage to individuals up to 150 percent of poverty and three tiers of subsidized coverage up to 300 percent of poverty. CommCare plans were sold through a new, state-run health insurance exchange.

In addition, the reform created a new online health insurance marketplace called the Connector, where individuals who did not qualify for free or subsidized coverage could purchase health insurance coverage. Unsubsidized CommChoice plans available through the Connector from several health insurers offered three regulated levels of coverage - bronze, silver, and gold. Young Adult plans with fewer benefits were also made available to individuals age 26 and younger. Individuals were also free to continue purchasing health insurance through their employers or to purchase health insurance directly from insurers.

The reform also implemented changes in the broader health insurance market. It merged the individual and small group health insurance markets. Existing community rating regulations, which required premiums to be set regardless of certain beneficiary characteristics of age and gender, remained in place, though it gave new authority to insurers to price policies based on smoking status. It also required all family plans to cover young adults for at least two years beyond loss of dependent status, up to age 26.

Another important aspect of the reform was an employer mandate that required employers with more than 10 full time employees to offer health insurance to employees and contribute a certain amount to premiums or pay a penalty. The legislation allowed employers to 
designate the Connector as its "employer-group health benefit plan" for the purposes of federal law.

The financing for the reform came from a number of different sources. Some funding for the subsidies was financed by the dissolution of existing state uncompensated care pools. ${ }^{2}$ Addressing costs associated with the reform remains an important policy issue.

The national health reform legislation passed in March 2010 shares many features of the Massachusetts reform, including an individual mandate to obtain health insurance coverage, new requirements for employers, expansions in subsidized care, state-level health insurance marketplaces modeled on the Massachusetts Connector, and new requirements for insurers to cover dependents to age 26, to name a few. For a summary of the national legislation, see Kaiser Family Foundation (2010). Taken together, the main characteristics of the reform bear strong similarity to those in the Massachusetts reform, and the impact of the Massachusetts reform should offer insight into the likely impact of the national reform.

As Chapter 58 was enacted recently, there has been relatively little research on its impact to date. Long (2008) presents results on the preliminary impact of the reform from surveys administered in 2006 and 2007. Yelowitz and Cannon (2010) examine the impact of the reform on coverage using data from the March 2006-2009 Supplements to the Current Population Survey (CPS). They also examine changes in self-reported health status in an effort to capture the effect of the reform on health. Using this measure of health, they find little evidence of health effects. The NIS discharge data allow us to examine utilization and health effects in much greater detail. Long et al. (2009) perform an earlier analysis using one fewer year of the same data. Long et al. (2009) and Yelowitz and Cannon (2010) find a decline in uninsurance among the population age 18 to 64 of 6.6 and 6.7 percentage points, respectively. We also rely on the CPS for preliminary analysis. Our estimates using the CPS are similar in magnitude to the prior studies, though our sample differs in that we include all individuals under age 65 and at all income levels. Our main results, however, focus on administrative data from hospitals. This builds on the existing literature by considering coverage changes specifically amongst those who were hospitalized, as well as extending the analysis beyond coverage alone to focus on hospital and preventive care.

\section{Description of the Data}

For our main analysis, we focus on a nationally-representative sample of hospital discharges. Hospital discharge data offer several advantages over other forms of data to examine the impact of Chapter 58. First, though hospital discharge data offer only limited information on the overall population, they offer a great deal of information on a population of great policy interest - individuals who are sick. This population is most vulnerable to changes in coverage due to the fact that they are already sick, and they disproportionately come from demographic groups that are at higher risk, such as minority groups and the indigent. Inpatient care also represents a disproportionate fraction of total health care costs. Second, hospital discharge data allow us to observe the insured and the uninsured, regardless of payer, and payer information is likely to be more accurate than it is in survey data. Third, hospital discharge data allow us to examine treatment patterns and some health outcomes in great detail. In addition, relative to the CPS, hospital discharge data allow us to examine changes in medical expenditure, subject to limitations discussed below. One disadvantage of

\footnotetext{
${ }^{2}$ In addition to the ability to re-appropriate funds from the uncompensated care pool, Massachusetts obtained a Medicaid waiver that allowed the reallocation of Disproportionate Share Hospital (DSH) payments towards the reduction of uninsurance. Thus, payments that previously went to hospitals treating a disproportionate share of Medicaid or uninsured were incorporated into the subsidies used to pay for expansions in coverage (Grady (2006)). Changes in DSH payments could have shifted incentives at some hospitals more than others (Duggan (2000)).
} 
hospital discharge data relative to the CPS is that the underlying sample of individuals in our data could have changed as a result of the reform. We use many techniques to examine selection as an outcome of the reform and to control for selection in the analysis of other outcomes.

Our data are from the Healthcare Cost and Utilization Project (HCUP) Nationwide Inpatient Sample (NIS). Each year of NIS data is a stratified sample of 20 percent of United States community hospitals, designed to be nationally representative. ${ }^{3}$ The data contain the universe of all hospital discharges, regardless of payer, for each hospital in the data in each year. Because a large fraction of hospitals appear in several years of the data, we can use hospital identifiers to examine changes within hospitals over time.

We focus on the most recently available NIS data for the years 2004 to 2008. Our full sample includes a total of 36,362,108 discharges for individuals of all ages. An advantage of these data relative to the March Supplement to the CPS is that they allow us to examine the impact of the reform quarterly instead of annually. Because some aspects of the reform, such as Medicaid expansions, were implemented immediately after the reform, but other reforms were staggered, we do not want to include the period immediately following the reform in the After or the Before period. To be conservative, we define the After reform period to include all observations in the third quarter of 2007 and later. The After period represents the time after July 1, 2007, when one of the most salient features of the reform, the individual health insurance mandate, took effect. We denote the During period as the year from 2006 Q3 through 2007 Q2, and we use this period to analyze the immediate impact of the reform before the individual mandate took effect. The Before period includes 2004 Q1 through 2006 Q2. ${ }^{4}$

In total, from 2004-2008, the data cover 42 states - Alabama, Alaska, Delaware, Idaho, Mississippi, Montana, North Dakota, and New Mexico are not available in any year because they did not provide data to the NIS. The data include the universe of discharges from a total of 3,090 unique hospitals, with 48 in Massachusetts. The unit of observation in the data and in our main analysis is the hospital discharge. To account for stratification, we use discharge weights in all summary statistics and regressions.

\section{Difference-in-Differences Empirical Results}

\subsection{Impact on Insurance Coverage in the Overall and Inpatient Hospital Populations}

We begin by considering the issue that was the primary motivation for the Massachusetts reform - the expansion of health insurance coverage. Before focusing on inpatient hospitalizations, we place this population in the context of the general population using data from the 2004 to 2009 March Supplements to the Current Population Survey (CPS). In most of our results, we focus on the nonelderly population because the reform was geared toward the nonelderly population (elderly with coverage through Medicare were explicitly excluded from purchasing subsidized CommCare plans, but they were eligible for Medicaid expansions if they met the income eligibility criteria). ${ }^{5}$

\footnotetext{
3“Community hospitals" are defined by the American Hospital Association as "all non-Federal, short-term, general, and other specialty hospitals, excluding hospital units of institutions" (Agency for Healthcare Research and Quality 2004 - 2007)). The sample is stratified by geographic region - Northeast vs. Midwest vs. West vs. South; control - government vs. private not-for-profit vs. private investor-owned; location - urban vs. rural; teaching status - teaching vs. non-teaching; and bed size - small vs. medium vs. large. Implicit stratification variables include state and three-digit zip code.

${ }^{4}$ Unfortunately, Massachusetts did not provide Q4 data to the NIS in 2006 or 2007. To address this limitation, we drop all data from all states in 2006 Q4 and 2007 Q4. Potential users of these data should note that to address this limitation, the NIS relabeled some data from the first three quarters of the year in 2006 and 2007 MA as Q4 data. Using information provided by NIS, we recovered the unaltered data for use here.
} 
Figure 1 depicts trends in total insurance coverage of all types among nonelderly in the CPS. The upper line shows trends in coverage in Massachusetts, and the lower line shows trends in coverage in all other states. From the upper line, it is apparent that Massachusetts started with a higher baseline level of coverage than the average among other states. The average level of coverage among the nonelderly in Massachusetts prior to the reform (2004-2006 CPS) was 88.2 percent. ${ }^{6}$ This increased to a mean coverage level of 93.8 percent in the 2008-2009 CPS. $^{7}$ In contrast, the remainder of the country had relative stable rates of nonelderly coverage: 82.7 percent pre-reform and 82.5 percent post-reform. For the entire population, including those over 65 , coverage in Massachusetts went from 89.5 percent to 94.5 percent for the same periods while the remainder of the country saw a small decline from 84.6 percent insured pre-reform to 84.4 percent insured post-reform. ${ }^{8}$

Appendix Table A1 formalizes this comparison of means with difference-in-differences regression results from the CPS. These results suggest that the Massachusetts reform was successful in expanding health insurance coverage in the population. The estimated reduction in nonelderly uninsurance of 5.7 percentage points represents a 48 percent reduction relative to the pre-reform rate of nonelderly uninsurance in Massachusetts. ${ }^{9}$ To some, the decrease in uninsurance experienced by Massachusetts may appear small. To put this in perspective, the national reform targets a reduction in uninsurance of a similar magnitude. The Centers for Medicare and Medicaid Services, Office of the Actuary, National Health Statistics Group, predicts a decrease in uninsurance of 7.1 percentage points nationally from 2009 to 2019 (Truffer et al. (2010)).

4.1.1. Regression Results on the Impact on Uninsurance-Using the NIS data, we begin by estimating a simple difference-in-differences specification. Our primary estimating equation is:

$$
Y_{d h t}=\alpha+\beta\left(M A^{*} \text { After }\right)_{h t}+\gamma\left(M A^{*} \text { During }\right)_{h t}+\sum_{h} \rho_{h}(\text { Hosp }=h)_{h}+\sum_{t} \varphi_{t} \text { YearQuarter }_{t}+\mathbf{X}_{d h t}^{\prime} \delta+\varepsilon_{d h t},
$$

where $Y$ is an outcome variable for hospital discharge $d$ in hospital $h$ at time $t$. The coefficient of interest, $\beta$, gives the impact of the reform - the change in coverage after the reform relative to before the reform in Massachusetts relative to other states. Analogously, $\gamma$

\footnotetext{
${ }^{5}$ Because the reform was geared toward the nonelderly, we considered using the elderly as an additional control group in our difference-in-differences estimates. However, we did not pursue this identification strategy for three reasons: first, the elderly were eligible for some elements of the reform; second, the elderly are less healthy overall and suffer from different types of health shocks than the younger individuals of interest to us; and third, we find some increases in coverage for the elderly. Although many assume that the elderly are universally covered through Medicare, some estimates suggest that 4.5 percent or more of the elderly population are not eligible for full federally subsidized coverage through Medicare Part A, so coverage increases are possible in this population (Gray et al. (2006), Birnbaum and Patchias (2008)).

${ }^{6}$ We follow the Census Bureau in defining types of coverage and uninsurance. These definitions and the associated code to implement them are available from http://www.census.gov/hhes/www/hlthins/hlthinsvar.html. For individuals who report having both Medicaid and Medicare ("dual eligibles"), we code Medicaid as their primary insurance type. We make the additional assumption that individuals who are covered by private health insurance but not by an employer-sponsored plan are in the private market unrelated to employment.

${ }^{7}$ Results from 2007 are difficult to interpret because the reform was in the midst of being implemented in March, when the CPS survey was taken. Medicaid expansions had occurred at that point but the individual mandate was not implemented until July 2007. We thus focus on the period that was clearly before the full reform - CPS March supplement answers from 2004-2006 - compared to 2008-2009. Note that we use more precise definitions of the periods before, during, and after the reform in the NIS, as described in the text. We have made these definitions as comparable as possible across all data sets.

${ }^{8}$ The initial coverage level in Massachusetts was clearly higher than the national average, though it was not a particular outlier. Using data from the 2004, 2005, and 2006 CPS, we rank states in terms of insurance coverage. In this time period, Massachusetts had the seventh highest level of coverage among the nonelderly in the US. It was one of 17 states with 88 percent or higher share of the population insured, and its initial coverage rate was only 1.7 percentage points higher than the 86.5 percent coverage rate in the median state.

${ }^{9}$ In tables that can be found in Kolstad and Kowalski (2010), we present estimates of the decline in uninsurance for each age, gender, income, and race category using the CPS.
} 
gives the change in coverage during the reform relative to before the reform in Massachusetts relative to other states. The identification assumption is that there were no factors outside of the reform that differentially affected Massachusetts relative to other states after the reform. We also include hospital and quarterly time fixed effects. Thus, identification comes from comparing hospitals to themselves over time in Massachusetts compared to other states, after flexibly allowing for seasonality and trends over time. We include hospital fixed effects to account for the fact that the NIS is an unbalanced panel of hospitals. Without hospital fixed effects, we are concerned that change in outcomes could be driven by changes in the sample of hospitals in either Massachusetts or control states (primarily the former since the sample is nationally representative but is not necessarily representative within each state) after the reform. ${ }^{10}$ Our preferred specification includes time and hospital fixed effects. ${ }^{11}$

For each outcome variable of interest, we also estimate models that incorporate a vector $\mathbf{X}$ of patient demographics and other risk adjustment variables. We do not control for these variables in our main specifications because we are interested in measuring the impact of the reform as broadly as possible. To the extent that the reform changed the composition of the sample of inpatient discharges based on these observable characteristics, we would obscure this effect by controlling for observable patient characteristics. Beyond our main specifications, the impact of the reform on outcomes holding the patient population fixed is also highly relevant. For this reason, in other specifications, we incorporate state-of-the-art risk adjusters, and we present a number of specifications focused on understanding changes in patient composition. We return to this in more detail below. In general, however, we find that though there is some evidence of selection, it is not large enough to alter the robustness of our findings with respect to coverage or most other outcomes.

We use linear probability models for all of our binary outcomes. Under each coeffcient, we report asymptotic 95 percent confidence intervals, clustered to allow for arbitrary correlations between observations within a state. Following Bertrand et al. (2004), we also report 95 percent confidence intervals obtained by block bootstrap by state, as discussed in Appendix A. In practice, the confidence intervals obtained through both methods are very similar. To conserve space, we do not report the block bootstrapped standard errors in some tables.

In addition to the specifications we present here, we consider a number of robustness checks to investigate the internal and external validity of our results. We find that the conclusions presented in Table 1 are robust to a variety of alternative control groups and do not appear to be driven by unobserved factors that are unique to Massachusetts. For brevity, we present and discuss these results in Appendix B.

Given our short time period, we are particularly concerned about pre-trends in Massachusetts relative to control states. In Figures 23 , and 4, we present quarterly trends for each of our outcome variables of interest for Massachusetts and the remainder of the country. Each line and the associated confidence interval are coefficient estimates for each quarter for Massachusetts and non-Massachusetts states in a regression that includes hospital fixed effects. The omitted category for each is the first quarter of 2004, which we set equal

\footnotetext{
${ }^{10}$ Restricting the sample to the balanced panel of the 52 hospitals that are in the sample in all possible quarters (2004 Q1 to 2008 Q4, excluding 2006 Q4 and 2007 Q4) eliminates approximately 98 percent of hospitals and 97 percent of discharges, likely making the sample less representative, so we do not make this restriction in our main specifications. However, in the last panel of Appendix Table 7 , we present our main specifications using only the balanced panel, and the results are not statistically different from the main results.

${ }^{11}$ It is possible that insurance coverage changes which hospital people visit, in which case the bias from the use of hospital fixed effects would be of ambiguous sign. However, we are not able to investigate this claim since we do not have longitudinal patient identifiers.
} 
to 0 . While the plots show slight variation, none of our outcomes of interest appear to have strong pre-reform trends in Massachusetts relative to control states that might explain our findings. 12

\subsubsection{Effects on the Composition of Insurance Coverage among Hospital}

Discharges-In this section, we investigate the effect of the Massachusetts reform on the level and composition of health insurance coverage in the sample of hospital discharges. We divide health insurance coverage (or lack thereof) into five mutually exclusive types Uninsured, Medicaid, Private, Medicare, and Other. CommCare plans and other government plans such as Workers' Compensation and CHAMPUS (but not Medicaid and Medicare) are included in Other. We estimate equation (1) separately for each coverage type and report the results in columns 1 through 5 of Table $1 .{ }^{13}$ We focus on results for the nonelderly here, and we report results for the full sample and for the elderly only in Table 5.

Column 1 presents the estimated effect of the reform on the overall level of uninsurance. We find that the reform led to a 2.31 percentage point reduction in uninsurance. Both sets of confidence intervals show that the difference-in-differences impact of the reform on uninsurance is statistically significant at the 1 percent level. Since the model with fixed effects obscures the main effects of $M A$ and $A f t e r$, we also report mean coverage rates in Massachusetts and other states before and after the reform. The estimated impact of Chapter 58 represents an economically significant reduction in uninsured discharges of roughly 36 percent (2.31/6.43) of the Massachusetts pre-reform mean. We present coefficients on selected covariates from this regression in column 1 of Appendix Table A3.

We see from the difference-in-differences results in column 2 of Table 1 that among the nonelderly hospitalized population, the expansion in Medicaid coverage was larger than the overall reduction in uninsurance. Medicaid coverage expanded by 3.89 percentage points, and uninsurance decreased by 2.31 percentage points. Consistent with the timing of the initial Medicaid expansion, the coefficient on $M A^{*}$ During suggests that a large fraction of impact of the Medicaid expansion was realized in the year immediately following the passage of the legislation. It appears that at least some of the Medicaid expansion crowded out private coverage in the hospital, which decreased by 3.06 percentage points. The riskadjusted coefficient in the last row of column 2 suggests that even after controlling for selection into the hospital, our finding of crowd-out persists. All of these effects are statistically significant at the 1 percent level.

To further understand crowd-out and the incidence of the reform on the hospitalized population relative to the general population, we compare the estimates from Table 1 coverage among those who were hospitalized - with results from the CPS - coverage in the overall population. In Appendix Table A1, we report difference-in-differences results by coverage type in the CPS. The coverage categories reported by the CPS do not map exactly to those used in the NIS. Insurance that is coded as private coverage in the NIS is divided into employer sponsored coverage and private coverage not related to employment in the CPS. Furthermore, the Census Bureau coded the new plans available in Massachusetts, CommCare and CommChoice, as "Medi-caid." 14 Thus the estimated impact on Medicaid is actually the combined effect of expansions in traditional Medicaid with increases in CommCare and CommChoice. Medicaid expansions are larger among the hospital discharge

\footnotetext{
${ }^{12}$ When we formalize this visual analysis in results not reported, we find slightly different trends in Massachusetts, some with statistical significance. However, the magnitude of these effects is generally small relative to the $M A^{*} A f t e r$ coefficients for each outcome. Taken together, this evidence suggests that our estimates are unlikely to be driven by differential pre-reform trends in Massachusetts.

${ }^{13}$ Because these represent mutually exclusive types of coverage, the coefficients sum to zero across the first five columns.
} 
population than they are in the CPS - a 3.89 percentage point increase vs. a 3.50 percentage point increase, respectively. Furthermore, the CPS coefficient is statistically lower than the NIS coefficient. It is not surprising to see larger gains in coverage in the hospital because hospitals often retroactively cover Medicaid-eligible individuals who had not signed up for coverage.

Comparing changes in types of coverage in the NIS to changes in types of coverage in the CPS, we find that crowd-out of private coverage only occurred among the hospitalized population. In Appendix Table A1, the magnitudes of the $M A^{*}$ After coefficients are 0.0345 and 0.0351 for ESHI and Medicaid respectively. That is, both employer-sponsored and Medicaid, CommCare or CommChoice coverage increased by a similar amount following the reform, and those increases were roughly equivalent to the total decline in uninsurance (5.7 percentage points). The only crowding out in Appendix Table A1 seems to be of nongroup private insurance, though this effect is relatively small at 0.86 percentage points. Combining coefficients for ESHI and private insurance unrelated to employment gives us a predicted increase in private coverage (as it is coded in the NIS) of 2.59 percentage points. This is in marked contrast with the 3.54 percentage point decrease in private coverage that we observe in the NIS.

Returning to the NIS, we look further at results from other specifications. Our results also indicate a statistically significant change in the number of non-elderly covered by Medicare. The magnitude of the effect, however, is quite small both in level of coverage and in change relative to the baseline share of non-elderly inpatient admissions covered by Medicare. Other coverage, the general category that includes other types of government coverage including CommCare, increased by a statistically significant 1.06 percentage points. We restrict the dependent variable to include only CommCare in specification 6. By definition, CommCare coverage is zero outside of Massachusetts and before the reform. CommCare increased by 1.24 percentage points. The coefficient is larger than the overall increase in Other coverage, though the difference in the coefficients is not statistically significant. As reported in specification 7 , the probability of having missing coverage information also increased after the reform, but this increase was small relative to the observed increases in coverage.

\subsection{Impacts on Health Care Provision}

Having established the impact of the Massachusetts reform on coverage, we next turn to our primary focus: understanding the impact of achieving near-universal health insurance coverage on health care delivery and cost. In the next four subsections, we estimate equation (1) with dependent variables that capture the decision to seek care, the intensity of services provided conditional on seeking care, preventive care, and hospital costs.

4.2.1. Impact on Hospital Volume and Patient Composition-One potential impact of the reform could be to increase the use of inpatient hospital services. Whether more people accessed health insurance after the reform is of intrinsic interest as this implies a change in welfare due to the policy (e.g. an increase in moral hazard through insurance or a decrease in ex ante barriers to accessing the hospital due to insurance). Beyond this, changes

\footnotetext{
${ }^{14} \mathrm{We}$ thank the Census Bureau staff for their rapid and thorough response to the many calls we made to confirm this decision on categorizing the new types of plans. Since the CommChoice plans are coded as Medicaid in the CPS, we are concerned that estimated increases in Medicaid coverage in the CPS should could lead to overestimates of crowd-out because the estimated Medicaid expansion could include individuals who transitioned from private market unsubsidized care to CommChoice unsubsidized care. To investigate this possibility, in unreported regressions, we divide the sample by income to exclude individuals who are not eligible for subsidized care. The results suggest an increase in "Medicaid" coverage for people above 300 percent of the FPL of 0.6 percentage points. Thus, the bulk of the effect on Medicaid reffects some form of publicly subsidized coverage and not unsubsidized CommChoice plans coded as Medicaid.
} 
in the composition of patients present an important empirical hurdle to estimating the causal impact of the reform on subsequent measures of care delivered. If the number of patients seeking care after the reform increased and the marginal patients differed in underlying health status, changes in treatment intensity could reffect this, rather than actual changes in the way care is delivered. We investigate this possibility in two ways: first, we examine changes in the number of discharges at the hospital level; second, we control for observable changes in the health of the patient pool and compare our results to specifications without controls.

In Table 2, we investigate selection into hospitals by estimating a series of specifications with the number of discharges at the hospital-quarter level as the dependent variable. In column 1 of Table 2, which includes hospital and quarterly fixed effects to mitigate the impact of changes in sample composition, the coefficient on $M A^{*}$ After indicates that the number of quarterly discharges for hospitals in Massachusetts was unchanged relative to other states following the reform. The coefficient estimate of 19 is small relative to the prereform quarterly discharge level of 5,616, and it is not statistically significant. In column 2, we re-estimate the model with the log of total discharges as the dependent variable to account for any skewness in hospital size. The coefficient on $M A^{*}$ After in this specification also indicates that the reform had no impact on the total volume of discharges. Columns 3 to 6 break down changes in discharges by age category (nonelderly and elderly). Among these subgroups we find no statistically significant change in total elderly or nonelderly discharges in either levels or logs. These findings suggest that any change in the composition of patients would have to have occurred through substitution since the total number of discharges remained unchanged. However, we are unlikely to pick up a relative change in discharges among the newly insured in our aggregate measure. ${ }^{15}$

To deal with changes in the patient population directly, we control for observable changes in the health of the patient pool using six sets of risk adjustment variables: demographic characteristics, the number of diagnoses on the discharge record, individual components of the Charlson Score measure of comorbidities, AHRQ comorbidity measures, All-Patient Refined Diagnosis Related Groups (APR-DRGs), and All-Payer Severity-adjusted Diagnosis Related Groups (APS-DRGs). We discuss these measures in depth in Appendix C. These measures are a valid means to control for selection if unobservable changes in health are correlated with the changes in health that we observe. We interpret our risk-adjusted specifications assuming that this untestable condition holds, with the caveat that if it does not hold, we cannot interpret our results without a model of selection.

In results presented in the second panel of Table 2, we estimate our model with a subset of our measures of patient severity as the dependent variable. For this exercise, we focus on the six sets of severity measures that are simplest to specify as outcome variables. This allows us to observe some direct changes in the population severity in Massachusetts after the reform. These results present a mixed picture of the underlying patient severity. For four of

\footnotetext{
${ }^{15}$ This is true because the newly insured are a small share of the population. From the CPS, approximately $12 \%$ of people were uninsured before Massachusetts reform. From Table 2, we see that the average Massachusetts hospital had 5,616 discharges before reform, of which $6.43 \%$ were for the uninsured (see Table 1). Thus, the insured $88 \%$ of the population was responsible for 5,254 discharges, and the uninsured $12 \%$ of the population was responsible for 361 discharges. The discharge rate was twice as high for the insured as for the uninsured. From our difference-in-differences results from the CPS, roughly half of the previously uninsured, $6 \%$ of the population, gained coverage. If these individuals, now insured, increased utilization such that had the same level of discharges as those previously insured, then we would expect that they would have $358(=5,254 * 6 / 88)$ discharges after reform. Since they already had $180(=361 *(6 / 12))$ discharges before reform, the change in their utilization rate would result in an additional $178(=358-180)$ discharges. Given that our $95 \%$ confidence interval on the hospital discharge regression in Table 2 is [-183, 220], we can only reject the null of no change in discharges if discharges change by more than 403 . Thus, we could not distinguish an increase in 178 discharges from no change in discharges. The newly insured would have to increase their utilization by 3.25 times $((3.25 * 180)$ $-180=405$ ) for us to detect the change $95 \%$ of the time.
} 
the six measures, we find no significant change in severity. Two of the severity measures, however, saw statistically significant changes after the reform. The results in specification 8 suggest that the average severity, measured by the Charlson score, increased following the reform. The model of APS-DRG charge weights suggests the opposite. Taken together, these results and the lack of any change in total discharges are not indicative of a consistent pattern of changes in the patient population within a given hospital in Massachusetts after the reform relative to before relative to other states.

Despite this general picture, and in light of the results in columns 8 and 13, for all of our outcome variables we estimate the same model incorporating the vector of covariates $\mathbf{X}$, which flexibly controls for all risk adjusters simultaneously. In general, our results are unchanged by the inclusion of these controls - consistent with the small estimated impact of the reform on the individual severity measures. If anything, we find that the main results are strengthened by the inclusion of covariates as we would expect with increased severity after the reform.

In column 7 of Table 2, we investigate the possibility that either hospital size increased or sampling variation led to an observed larger size of hospitals after the reform relative to before the reform by using a separate measure of hospital size as the dependent variable. This measure, Hospital Bedsize, which we link to our data from the American Hospital Association (AHA) annual survey of hospitals, reports the number of beds in each hospital. The coefficient estimate indicates that hospital size remained very similar after the reform for the hospitals in the sample in both periods. The coefficient, which is not statistically significant, suggests that if anything, there was a decrease in hospital size by 21 beds.

4.2.2. Impact on Resource Utilization and Length of Stay-Moving beyond the question of the extensive margin decision to go to the hospital or to admit a patient to the hospital, we turn to the intensity of services provided conditional on receiving care. The most direct measure of this is the impact of the reform on length of stay. As discussed earlier, we expect length of stay to increase in response to increased coverage if newly insured individuals (or their physician agents) demand more treatment - that is, if moral hazard or income effects dominate. Alternately, we expect length of stay to decrease in response to increased coverage if newly insured individuals are covered by insurers who are better able to impact care through either quantity restrictions or prices - that is, if insurer bargaining effects dominate. Changes in insurer composition could also change the bargaining dynamic or prices paid. Expansions in Medicaid or subsidized CommCare plans might lead to relatively different payment incentives. Length of stay may also decline if insurance alters treatment decisions, potentially allowing substitution between inpatient and outpatient care or drugs that would not have been feasible without coverage. ${ }^{16}$ To investigate these two effects, we estimate models of length of stay following equation (1) in both levels and logs of the dependent variable.

The results in specifications 8 and 9 of Table 1 show that length of stay decreased by 0.05 days on a base of 5.42 days in the levels specification - a decline of approximately 1 percent. Estimates in column 2 show a 0.12 percent decline in the specification in logs. Because taking logs increases the weight on shorter stays, this difference suggests that the reform had a larger impact on longer stays. In unreported results, we also estimate models of

\footnotetext{
${ }^{16}$ Discussions with physicians suggest that a key challenge in discharging a patient from the hospital is determining the availability and quality of follow up care (e.g. access to a primary care physician for a follow up visit, support to pick up and take prescribed medicines or space in skilled nursing or long term care facility). Insurance potentially plays an important role in this transition. In the absence of follow up care physicians may keep patients in the inpatient setting despite potentially much more efficient settings in which their care could be provided.
} 
the probability a patient exceeds specific length of stay cutoffs. The results validate the findings in columns 1 and 2. Patients were roughly 10 percent less likely to stay beyond 13 and/or 30 days in Massachusetts after the reform. These effects were statistically significant. The probabilities of staying beyond shorter cutoffs $(2,5$, and 9 days) were unchanged. The results suggest that patients were significantly more likely to stay at least 3 days though the magnitude of the coefficient suggests an increase of only 1 percent relative to the baseline share.

To address the concern that our estimated reduction in length of stay was driven by differential selection of healthier patients into the hospital after the reform in MA, we report results controlling for risk adjustment variables in the last row of both panels in Table 1. The estimated decreases in length of stay and log length of stay are at least twice as large in the specifications that include risk adjusters. Holding the makeup of the patient pool constant, length of stay clearly declined. The comparison between the baseline and risk-adjusted results suggests that, patients requiring longer length of stays selected into the patient pool in post-reform Massachusetts.

One plausible mechanism for the decline in length of stay is limited hospital capacity. As with patient severity, capacity constraints are interesting in their own right, but they could bias our estimates of other reform impacts. Capacity itself is endogenous and may have changed with the reform, as we saw in the model with number of beds as the dependent variable. 17

Our results can provide some insight into whether changes in length of stay seem to be related to capacity by comparing the additional capacity that resulted from the decrease in length of stay to the magnitude of the change in discharges. Because hospitals care about total changes in capacity, not just among the nonelderly, we use estimates for the change in length of stay among the entire population, a decrease of .06 days on a base of 5.88 days. The new, lower average length of stay is $5.88-0.06=5.82$ days. This would make room for an extra $(0.06 * 5,616) /(5.88-0.06)=58$ discharges. An extra 58 discharges exceeds the estimated increase of 19 discharges (from column 1 of Table 2). We note, however, that the upper bound of the 95 percent confidence interval for the estimated change in total discharges is greater than 58. Thus, decreased length of stay could have been a response to increased supply side constraints, although this explanation would be more convincing if the point estimate for the change in the number of discharges were positive and closer to change in the supply-side constraint of $58 .{ }^{18}$

4.2.3. Impact on Access and Preventive Care-One potentially important role of insurance is to reduce the cost of obtaining preventive care that can improve health and/or reduce future inpatient expenditures. In this case, moral hazard can be dynamically efficient by increasing up front care that results in future cost reductions (Chernew et al. (2007)). One manifestation of a lack of coverage that has received substantial attention is the use of the emergency room (ER) as a provider of last resort. If people do not have a regular point of access to the health care system and, instead, go to the emergency room only when they become sufficiently sick, such behavior can lead them to forego preventive care and

\footnotetext{
${ }^{17}$ In a simple queuing model of hospital demand and bed size, Joskow 1980) shows that, under general assumptions, the probability that a patient is turned away from a hospital is endogenously determined by the hospital when it selects a reserve ratio (the difference between the total number of beds and the average daily census (ADC) relative to the standard deviation in arrival rates). Because beds are a fixed cost, capacity and utilization are a source of scale economies for hospitals. If hospitals seek to improve efficiency we would expect to see improved throughput in an effort to lower cost. One means of accomplishing this is to make smaller increases in capacity relative to demand following the reform.

18 Although we do not find much evidence for capacity constraints in the inpatient setting, there is anecdotal evidence for capacity constraints in the outpatient primary care setting. Investigating constraints in that setting is beyond the scope of this paper.
} 
potentially increase the cost of future treatment. In addition, emergency room care could be ceteris paribus more expensive to provide than primary care because of the cost of operating an ER relative to other outpatient settings. Although we do not observe all emergency room discharges, we can examine inpatient admissions from the emergency room as a rough measure of emergency room usage. A decrease in admissions from the ER after the reform is evidence that a subset of the population that previously accessed inpatient care through the emergency room accessed inpatient care through a traditional primary care channel or avoided inpatient care entirely (perhaps by obtaining outpatient care).

In specification 10 of Table 1, we examine the impact of the reform on discharges for which the emergency room was the source of admission. We see that the reform resulted in a 2.02 percentage point reduction in the fraction of admissions from the emergency room. Relative to an initial mean in Massachusetts of 38.7 percent this estimate represents a decline in inpatient admissions originating in the emergency room of 5.2 percent. The risk-adjusted estimate reported in the bottom row of specification 10 is very similar. ${ }^{19}$

As a further specification check, we decompose the effect by zip code income quartile. ${ }^{20}$ To the extent that income is a proxy for ex ante coverage levels, we expect larger declines in inpatient admissions originating in the ER among relatively poorer populations. We present these results in Table 5. We find that the reduction in emergency admissions was particularly pronounced among people from zip codes in the lowest income quartile. As reported in the second panel of Table 5, the coefficient estimate suggests a 12.2 (= $-0.0570 / .4665$ ) percent reduction (significant at the 1 percent level) in inpatient admissions from the emergency room. The effect in the top two income quartiles, on the other hand, is not statistically significantly different from zero (coefficient estimate of -0.0107 and 0.0098 for the 3rd and 4th income quartiles respectively). Taken together, these results suggest that the reform did reduce use of the ER as a point of entry into inpatient care. This effect was driven by expanded coverage, particularly among lower income populations.

Our results focus solely on emergency room visits that resulted in a hospitalization. This group should be of particular interest to economists and policy makers. They are relatively sick since an admission was ultimately deemed necessary, and would likely benefit from access to outpatient or other care. Furthermore, this is likely to be a much higher cost group where improvements in access may yield efficiency gains. Nevertheless, many ER visits do not result in admission to the hospital. In subsequent work, Miller (2011) studies the universe of ER visits in Massachusetts directly. Her study is a useful complement to our results on this question. She finds reductions in ER admissions, primarily for preventable and deferrable conditions that would not result in inpatient admissions.

In addition to the use of the ER, we are interested in measuring whether providing health insurance directly affects access to and use of preventive care. To investigate the impact of the reform on prevention we use a set of measures developed by the Agency for Healthcare Research and Quality (AHRQ): the prevention quality indicators (PQIs). ${ }^{21}$ See Appendix D

\footnotetext{
${ }^{19}$ We note that these results differ somewhat from discussions in media and policy circles (Kowalczyk (2010)). Our analysis differs for a few reasons. First, we are focused solely on inpatient admissions from the ER. While this limits the scope of our results, it allows us to focus on a population of particular importance, the relatively sick and costly populations who, ultimately, receive care in the hospital. A second issue with the existing discussion of Massachusetts ER usage is the lack of a control group. Our results take into account trends in ER usage nationwide that are likely to be changing over time. Using this approach, we are better able to account for changes in ER usage unrelated to the reform that affect MA, though we note that our findings do not appear to be driven by differential trends in states other than Massachusetts (see Figure 2).

${ }^{20}$ In results not shown, we decompose the effect by race, gender and income, and age. The results are not shown here in an effort to conserve space, but they are available in Kolstad and Kowalski 2010) Additionally, we present an analog to Table 5 using CPS data can be found in Appendix Table A2

${ }^{21}$ We thank Carlos Dobkin for suggesting the use of these indicators.
} 
for more details on these measures. These measures were developed as a means to measure the quality of outpatient care using inpatient data, which are more readily available. The appearance of certain preventable conditions in the inpatient setting, such as appendicitis that results in perforation of the appendix, or diabetes that results in lower extremity amputation, is evidence that adequate outpatient care was not obtained. All of the prevention quality measures are indicator variables that indicate the presence of a diagnosis that should not be observed in inpatient data if adequate outpatient care was obtained.

One concern in using these measures over a relatively narrow window of time is that we might not expect to see any impact of prevention on inpatient admissions. However, validating these measures with physicians suggest that the existence of PQI admissions is likely due to short term management of disease in an outpatient setting (e.g. cleaning and treating diabetic foot ulcers to avoid amputations due to gangrene), that we expect would be manifest within the post-reform period. ${ }^{22}$ Interpreted with different emphasis, these measures also capture impacts on health through averted hospitalizations. We run our difference-and-difference estimator separately for each quality measure using the binary numerator as the outcome variable, and the denominator to select the sample.

Table 3 presents regression results for each of the prevention quality indicators. Each regression is a separate row of the table. In the first row, the outcome is the "Overall PQI" measure suggested by AHRQ - a dummy variable that indicates the presence of any of the prevention quality indicators on a specific discharge. PQI 02 is excluded from this measure because it has a different denominator. We find little overall effect in the base specification. One advantage of examining this measure relative to the individual component measures is that doing so mitigates concerns about multiple hypothesis testing. The following rows show that of the 13 individual PQI measures, 3 exhibit a statistically significant decrease, 9 exhibit no statistically significant change, and 1 exhibits a statistically significant increase. Taken together, these results suggest that there may have been small impacts on preventive care, but little overall effect in reducing the number of preventable admissions.

We also estimate the model including controls for severity. If the impact of insurance or outpatient care on the existence of a PQI varies in patient severity, it is possible that the small estimated effects mask a compositional effect of the inpatient population after the reform. That is, if relatively severe patients are more likely to be hospitalized with a PQI, regardless of the outpatient care they receive, then estimates that hold the patient population fixed provide a better estimate for the impact of the reform on preventive care. These results are presented in the second column of Table 3. For the overall PQI measure, the coefficient on $M A^{*}$ After is -0.0023 and is statistically significant at the 1 percent level. Compared to the baseline rate of PQIs, this corresponds to a decline of 2.7 percent in preventable admissions. Results for the individual measures tell a similar story. Taken together, these results suggest that there was a small overall effect of the reform on preventable admissions but, holding the severity of the population fixed, there were significant declines. We find that, if anything, the inpatient population was more severe after the reform. Thus comparing the two coefficients both with and without risk adjustment suggests that the effect of the reform on reducing preventable admissions was largest among relatively less severe patients.

To supplement our analysis of preventive care, we also estimate models of prevention using data from the BRFSS for years 2004-2009. The BRFSS is a state-based system of health surveys that collects information on health risk behaviors, preventive practices, and health

\footnotetext{
${ }^{22}$ We thank Dr. Katrina Abuabara for discussing each of these PQI measures and the associated treatment regime and potential for inpatient admission.
} 
care access. For more information on the BRFSS, see Appendix E. Table 4 column 1 presents the differences-in-differences estimate for the impact of reform on those reporting they have health insurance coverage. Consistent with the results from the CPS, we a roughly 5 percent increase in coverage after the reform relative to before the reform in Massachusetts relative to other states. The remaining seven columns present results that are relevant to outpatient and preventive care. In column 2, we see a significant increase of 1.26 percent in individuals reporting they had a personal doctor. The reform also led to a decrease of 3.06 percentage points in individuals reporting they could not access care due to cost. Columns 4-8 present difference-in-differences estimates for the impact of the reform on a set of direct measures of preventive care. We find little overall impact in the population. The only statistically significant estimate is for the impact of the reform on receiving a flu vaccination.

4.2.4. Impact on Hospital Costs-In this section, we investigate the impact of the reform on hospital costs. The cost impact, as we discuss above, depends on the relative changes in incentives facing hospitals and physicians in treatment and investment decisions. In the presence of moral hazard or income effects, we expect that the large coverage expansion in Massachusetts would lead the newly insured to seek additional care and, conditional on use, more expensive care (Pauly (1968); Manning et al. (1987); Kowalski (2009)). Insurers are also able to negotiate lower prices for care and, in the case of managed care plans, address treatment decisions directly through quantity limits (i.e. prior authorization rules that require a physician to get approval from the insurer in order for a procedure to be reimbursed, etc.) (Cutler et al. (2000)). Increased coverage through Medicaid or other insurers with relatively low reimbursement could mute the incentives for the provision of costly care. Furthermore, insurance could alter the way hospital care is produced making transitions in care easier or facilitating substitution of treatments to lower cost, outpatient settings or drugs. Thus, increases in coverage could lead to a countervailing decrease in cost with insurance coverage. Consequently, it is an empirical question whether increases in health insurance coverage among the hospitalized population will raise or lower cost.

To measure hospital costs directly, we obtained hospital level all-payer cost to charge ratios. Hospitals are required to report these ratios to Medicare on an annual basis. The numerator of the ratio represents the annual total costs of operating the hospital such as overhead costs, salaries, and equipment. Costs only include the portion of hospital operations for in-patient care; they do not include the cost of uncompensated care, which presumably declined with the increase in insurance coverage. The denominator of this ratio represents annual total charges across all payers, which we observe disaggregated by discharge in the NIS. With our information on total charges from the NIS, we can get an accurate measure of total costs at the hospital level. Several papers in the economics literature measure total costs at the discharge level by deflating total charges by the cost to charge ratio (see Almond et al. (2010)). However, since there is no variation in observed costs at a level finer than the hospital level, estimating such a regression requires the strong assumption that the ratio of costs to charges is the same for all discharges within the hospital. Since we are interested in hospital-level costs, we need not impose this assumption, and we can focus on results at the hospital level.

The bottom panel of Table 2 presents difference-in-differences estimates for the impact of the reform on hospital costs using a variety of specifications. The first column presents estimates in levels. The coefficient estimate of 4.17 is statistically significantly different from zero. The logarithmic specification in column 2 yields a negative estimate for the impact of the reform on cost, though the coefficient is insignificant. The difference between the two, can be explained by the fact that the logarithmic specification takes into account 
trends in growth for both treatment and control groups. That is, Massachusetts had a differential trend in cost growth relative to the rest of the country before the reform. The log specification results indicate that this trend was not altered by the expansion in coverage relative to trends before and after the reform in the remainder of the country. The plots in Figure 4, which depict cost trends in Massachusetts and other states for the outcomes in Table 2, show that Massachusetts had a higher rate of cost growth as compared to other states before the reform. After the reform, Massachusetts relative costs appear to be in line with their pre-reform trend.

In the next columns, and in the bottom plots in Figure 4, we model cost per day and discharge, to account for changes in cost that may be due to changes in the intensity or total volume of patients treated. Both results are consistent with the levels regression in column 1 and suggest that cost growth was largely unchanged by the expansion in coverage in Massachusetts. Taken together, our results suggest that the Massachusetts reform did not increase the cost of hospital care relative to the baseline trend in cost growth. Thus, the Massachusetts reform did not appear to "bend the cost curve" upward or downward.

\section{Implications for National Reform}

While the impact of Massachusetts reform is of intrinsic interest, our results are also of broader interest given the similarities between the Massachusetts reform and the national reform. Without far more stringent modeling assumptions, it is difficult to predict the impact of coverage expansions at the national level. Nevertheless, our results do provide some broad predictions for national reform.

We find that the policy tools employed in Massachusetts expanded coverage among the previously uninsured. In the overall population, roughly half of new coverage was from private sources and the other half was from subsidized sources. Within the hospitalized population, we find some evidence for crowd-out of private coverage by subsidized coverage. The magnitude of the coverage increase under national reform could differ because several policy parameters, such as subsidies and penalties, have different magnitudes. Under national reform, the Congressional Budget Office predicts a reduction in uninsurance of 30 million people or roughly 8.4 percentage points (Congressional Budget Office (2012)). This estimate, along with the Centers for Medicare and Medicaid Services estimate of 7.1 percentage points (Truffer et al. 2010)), is slightly larger than reduction in coverage we find in Massachusetts, but they are of a comparable magnitude, suggesting extrapolating our broad findings is reasonable.

Subject to the caveat that some specific features of the Massachusetts experience that might make our results less valid in predicting the impact of the national reform, our results suggest that the national reform will likely result in reductions in length of stay, fewer preventable admissions, and fewer admissions from the emergency room. In Massachusetts, declines in admissions from the emergency room are largest among those with the lowest incomes, but Massachusetts is a wealthy state. To the extent that larger and poorer states have a greater share of the population at lower income levels, the impact on ER utilization could be even larger. However, some of our results could be specific to the hospital market in Massachusetts. Massachusetts, particularly the Boston area, has many large, prestigious medical centers. It is also a relatively concentrated hospital market. Additional coverage or changes in insurer market power might have different effects in other settings.

We find that the Massachusetts reform did not lower hospital cost growth in the aggregate. However, cost impacts are likely to be different under national reform. Massachusetts financed health reform largely through the reallocation of money already allocated for specific programs like the uncompensated care pool and DSH payments. The national 
reform also includes changes in Medicare financing that could affect incentives at the hospital level. These changes include payment reductions for Medicare Advantage and the introduction of new payment models including bundled payments and Accountable Care Organizations. The latter provides potentially very different incentives for care delivery because it provides incentives for primary care doctors to lower cost.

\section{Conclusion}

In this paper, we show that the Massachusetts health insurance reform expanded coverage among the inpatient hospital population by approximately 36 percent relative to its prereform level. Among this population, we see some evidence of the crowd-out of private coverage by subsidized coverage, but we do not find evidence for crowd-out in the general population, suggesting that the incidence of crowd-out differs by health status.

This paper is the first to examine the effect of Massachusetts health insurance reform on hospital outcomes. We show declines in length of stay and admissions from the emergency room following the reform. Our results, while sensitive to the inclusion of controls for patient severity, also suggest that prevention increased outside of hospitals, resulting in a decline in inpatient admissions for certain preventable conditions, reffecting a likely health impact for individuals susceptible to these conditions. In the midst of these gains, we find no evidence that hospital cost growth increased. We are unable to make precise welfare statements as we do not capture increased costs to the government and to the purchasers of health insurance that resulted from the reform. As our research progresses, we aim to answer other economics questions using variation by health insurance reform in Massachusetts.

\section{Acknowledgments}

Toby Chaiken, Andrew Maleki, Doug Norton, Michael Punzalan, Aditi Sen, and Swati Yanamadala provided excellent research assistance. C. Lanier Benkard, Joseph Doyle, Mark Duggan (the editor), Amy Finkelstein, Sherry Glied, Dana Goldman, Jonathan Gruber, Kate Ho, Jill Horwitz, Rob Huck-man, Kosali Simon, Jonathan Skinner, Erin Strumpf, Ebonya Washington, Heidi Williams, and anonymous referees provided helpful feedback. We thank the Schaeffer Center at USC. We also thank seminar participants at the University of Connecticut, Columbia University, the University of Illinois, the University of Lausanne, Case Western, Rice/University of Houston, the NBER Summer Institute, the Louis and Myrtle Moskowitz Workshop on Empirical Health Law and Business at the University of Michigan, and the 2nd HEC Montreal IO and Health Conference. Mohan Ramanujan and Jean Roth provided invaluable support at the NBER. Remaining errors are our own.

\section{References}

Agency for Healthcare Research and Quality. Healthcare Cost and Utilization Project (HCUP). Rockville, MD: Apr. 2004-2007 HCUP Nationwide Inpatient Sample (NIS). www.hcupus.ahrq.gov/nisoverview.jsp

Agency for Healthcare Research and Quality. AHRQ Quality Indicators Software Download. Rockville, MD: Apr. 2007a http://www.qualityindicators.ahrq.gov/software.htm

Agency for Healthcare Research and Quality. Pediatric Safety Indicators Download. AHRQ Quality Indicators. Rockville, MD: Mar. 2007b http://www.qualityindicators.ahrq.gov/pqidownload.htm

Almond, Douglas, Jr; Doyle, Joseph J.; Kowalski, Amanda E.; Williams, Heidi. Estimating Marginal Returns to Medical Care: Evidence from At-Risk Newborns. Quarterly Journal of Economics. 2010; 125(2):591-634. [PubMed: 20634927]

Bertrand, Marianne; Duflo, Esther; Mullainathan, Sendhil. How Much Should We Trust Differencesin-Differences Estimates?*. Quarterly Journal of Economics. 2004; 119(1):249-275.

Birnbaum, Michael; Patchias, Elizabeth. Medicare Coverage for Seniors: How Universal Is It and What Are the Implications?*. Paper presented at the annual meeting of the APSA 2008 Annual Meeting, Hynes Convention Center; Boston, Massachusetts,. August 28, 2008; 2008. http:// www.allacademic.com/meta/p281081index.html 
Card, David; Dobkin, Carlos; Maestas, Nicole. The Impact of Nearly Universal Insurance Coverage on Health Care Utilization: Evidence from Medicare. American Economic Review. 2008; 98(5):22422258. [PubMed: 19079738]

Charlson, Mary E.; Pompei, Peter; Ales, Kathy L.; Ronald MacKenzie, C. A New Method of Classifying Prognostic Comorbidity in Longitudinal Studies: Development and Validation. Journal of Chronic Diseases. 1987; 40(5):373-383. [PubMed: 3558716]

Chernew, Michael E.; Rosen, Allison B.; Mark Fendrick, A. Value-Based Insurance Design. Health Affairs. 2007; 26(2):w195. [PubMed: 17264100]

Elmendorf, Douglas, director. Congressional Budget Office. Updated Estimates for the Insurance Coverage Provisions of the Affordable Care Ac, 2012. Available at http://www.cbo.gov

Currie, Janet; Gruber, Jonathan. Health Insurance Eligibility, Utilization of Medical Care, and Child Health. The Quarterly Journal of Economics. 1996; 111(2):431-466.

Cutler, David M.; Gruber, Jonathan. Does Public Insurance Crowd Out Private Insurance. The Quarterly Journal of Economics. 1996; 111(2):391-430.

Cutler, David M.; McClellan, Mark; Newhouse, Joseph P. How Does Managed Care Do It? The RAND Journal of Economics. 2000; 31(3):526-548. [PubMed: 11503704]

Dranove, David; Satterthwaite, Mark A. Monopolistic Competition When Price and Quality are Imperfectly Observable. RAND Journal of Economics. 1992; 23(4):518-534.

Duggan, Mark G. Hospital Ownership and Public Medical Spending. Quarterly Journal of Economics. 2000; 115(4):1343-1373.

Finkelstein, Amy. The Aggregate Effects of Health Insurance: Evidence from the Introduction of Medicare. The Quarterly Journal of Economics. 2007; 122(1):1-37.

Finkelstein, Amy; Taubman, Sarah; Wright, Bill; Bernstein, Mira; Gruber, Jonathan; Newhouse, Joseph P.; Allen, Heidi; Baicker, Katherine. the Oregon Health Study Group. The Oregon Health Insurance Experiment: Evidence from the First Year. The Quarterly Journal of Economics. 2012 page Forthcoming.

Glied, Sherry; Zivin, Joshua. How Do Doctors Behave When Some (but Not All) of Their Patients are in Managed Care? Journal of Health Economics. 2002; 21(2):337-353. [PubMed: 11939245]

Grady, April. The Massachusetts Health Reform a Brief Overview. Congressional Research Service Report for Congress; 2006.

Gray, Bradford H.; Scheinmann, Roberta; Rosenfeld, Peri; Finkelstein, Ruth. Aging without Medicare? Evidence from New York City. Inquiry. 2006; 43(3):211-221. [PubMed: 17176965]

Gruber, Jonathan; Kleiner, Samuel A. NBER Working Paper. 2010. Do Strikes Kill? Evidence from New York State; p. 15855

HSS, Inc. Definitions Manual for All-Payer Severity-adjusted DRG (APS-DRGs) Assignment. Germantown, MD: 2003. http://www.hcup-us.ahrq.gov/db/nation/nis/ APSDRGsDefManualV26Public.pdf

Joskow, Paul L. The Effects of Competition and Regulation on Hospital Bed Supply and the Reservation Quality of the Hospital. The Bell Journal of Economics. 1980:421-447.

Kaiser Family Foundation. Side-by-side comparison of major health care reform proposals. Mar. 2010 http://www.kff.org/healthreform/upload/housesenatebillfinal.pdf

Kingsdale, Jon. Implementing Health Care Reform in Massachusetts: Strategic Lessons Learned. Health Affairs. 2009; 28(4):w588. [PubMed: 19477873]

Kolstad, Jonathan T.; Kowalski, Amanda E. NBER Working Paper. 2010. The impact of health care reform on hospital and preventive care: Evidence from massachusetts; p. 16012

Kowalczyk, Liz. Emergency room visits grow in mass. The Boston Globe; Jul. 2010

Kowalski, Amanda. NBER Working Paper. 2009. Censored Quantile Instrumental Variable Estimates of the Price Elasticity of Expenditure on Medical Care; p. 15085

Long, Sharon. On the Road to Universal Coverage: Impacts of Reform in Massachusetts at One Year. Health Affairs. 2008; 27(4):w270. [PubMed: 18522948]

Long, Sharon K.; Stockley, Karen; Yemane, Alshadye. Another Look at the Impacts of Health Reform in Massachusetts: Evidence Using New Data and a Stronger Model. American Economic Review. 2009; 99(2):508. 
Manning, Willard G.; Newhouse, Joseph P.; Duan, Naihua; Keeler, Emmett; Benjamin, Bernadette; Leibowitz, Arleen; Susan Marquis, M.; Zwanziger, Jack. Health Insurance and the Demand for Medical Care: Evidence from a Randomized Experiment. The American Economic Review. 1987; 77(3):251-277. [PubMed: 10284091]

McDonough, John E.; Rosman, Brian; Phelps, Fawn; Shannon, Melissa. The Third Wave of Massachusetts Health Care Access Reform. Health Affairs. 2006; 25(6):w420. [PubMed: 16973653]

Miller, Sarah. Mimeo. 2011. The effect of insurance on emergency room visits: An analysis of the 2006 massachusetts health reform.

Pauly, Mark V. The Economics of Moral Hazard: Comment. The American Economic Review. 1968:531-537.

Quan, Hude; Sundararajan, Vijaya; Halfon, Patricia; Fong, Andrew; Burnand, Bernard; Luthi, JeanChristophe; Saunders, Duncan L.; Beck, Cynthia A.; Feasby, Thomas E.; Ghali, William A. Coding Algorithms for Defining Comorbidities in ICD-9-CM and ICD-10 Administrative Data. Medical Care. 2005; 43(11):1130. [PubMed: 16224307]

Robinson, James C.; Luft, Harold S. Competition and the Cost of Hospital Care, 1972 to 1982. Journal of the American Medical Association. 1987; 257(23):3241. [PubMed: 3586247]

Kingsdale, Jon, Executive DirectorThe Massachusetts Health Insurance Connector Authority. Report to the Massachusetts Legislature: Implementation of the Health Care Reform Law. 2008; 58:20062008. Available at www.mahealthconnector.org.

Truffer, Christopher J.; Keehan, Sean; Smith, Sheila; Cylus, Jonathan; Sisko, Andrea; Poisal, John A.; Lizonitz, Joseph; Kent Clemens, M. Health Spending Projections through 2019: The Recession's Impact Continues. Health Affairs. 2010; 29(3):522. [PubMed: 20133357]

Yelowitz, Aaron; Cannon, Michael F. The Massachusetts Health Plan: Much Pain, Little Gain. Policy Analysis. Jan. 2010 http://www.cato.org/pubdisplay.php?pubid=11115

\section{Appendix A. Block Bootstrap}

Since our main identifying variation is at the state-time level, we follow Bertrand et al. (2004), and block bootstrap our confidence intervals by state. Doing so allows for an arbitrary variance-covariance matrix within states across time. In this section, we discuss some implementation details that are not discussed by Bertrand et al. (2004). First, the empirical simulation results using the CPS presented by Bertrand et al. (2004) assume that half of the states are treated and the other half are untreated. Since we have only one treated state, it is only sampled in approximately one third of block bootstrap draws. In these draws, the difference-in-differences coefficient on $M A^{*}$ After cannot be estimated. In practice, we include these replications in the bootstrap sample to estimate the confidence intervals on the other coefficients without bias. We use a large number of bootstrap replications - 1,000 - so that the confidence intervals on our coefficient of interest are still based on a large number of bootstrap replications. ${ }^{23}$

Second, all of our regressions are weighted. To address weighting within our block bootstrap procedure, we sample states with replacement. Within a state, the sum of the weights does not change because all observations from a given state are drawn at once. However, the sum of the weights varies across regressions because not all states are sampled and some states are sampled more than once.

\footnotetext{
${ }^{23}$ Difficulties in the block bootstrap procedure aside, we acknowledge that having only one treated state potentially limits the external validity of our results. To address this limitation, we consider level and trend differences between MA and other states, which we discuss in Section 4.1.1.
} 


\section{Appendix B. Robustness of Insurance Results}

One potential concern about the external validity of our results is that Massachusetts could differ from the remainder of the country in ways that we do not observe, and these differences could lead to changes in coverage at the same time that the reform was implemented. Such differences could be due, for example, to factors that affected the entire Northeast. Alternately, it could be due to factors that affected states with relatively low levels of uninsurance. To account for potential unobserved differences that are correlated with observed differences in uninsurance, we estimate a series of specifications in our nonelderly sample, in which we restrict the comparison groups to states most similar to Massachusetts. We present these results in Appendix Table 7.

We first examine changes in uninsurance. When we restrict the comparison group of hospitals to hospitals in the Northeast Census division in the second panel, the impact of the reform on uninsurance is smaller than it is in the preferred specification, reproduced in the first panel. As reported in the means at the bottom of the column, the initial level of insurance coverage in the comparison states in the Northeast Census division was similar to the initial level of insurance coverage in the comparison states in the national sample. Similarly, in the third panel, when we restrict the comparison group to include only New England states, which had an initial lower but not statistically lower rate of uninsurance than Massachusetts, the estimated impact of the reform falls to a 1.59 percentage point reduction in uninsurance. This is statistically smaller than the baseline effect, but it remains significantly different from zero at the 1 percent level despite the much smaller sample size. To investigate the possibility that this change in magnitude is due to the limited health reforms that occurred in 2006 in Maine, Vermont and San Francisco, California, in column 4, we estimate the main specification in the full sample but we exclude Maine, Vermont, and California. Reassuringly, our point estimate remains unchanged from our main specification. As an alternative specification check, we estimate the same specification on the sample of the 25 states with the highest levels of nonelderly insurance coverage before the reform in the CPS. Our point estimate is not statistically different from that in the main specification.

In the remaining columns of Appendix Table A4, we present similar specifications for each of our main outcomes of interest. In general, our quantitative conclusions as well as our qualitative conclusions are unchanged when we change the group of comparison states. Our emergency admission result is particularly robust.

An additional issue in extrapolating from our Massachusetts results is that Massachusetts had a relatively smaller potential increase in insurance due to its high baseline level. If the cost of expanding coverage is convex, we expect larger reductions in uninsurance from the same policies in locations with higher baseline levels of uninsurance. We could test this proposition if another state with a different baseline level of uninsurance enacted the same policies. In the absence of such a natural experiment, we look for suggestive evidence in support of this hypothesis by examining the effect of the reform by baseline levels of insurance coverage within Massachusetts on the hospital level.

In Appendix Table A5, we divide hospitals based on their initial level of insurance coverage in the pre-reform period. Because not all hospitals in the sample were in the pre-reform data, we first restrict the sample to hospitals that appear at least once in the sample in the Before period. These results are presented in the second panel. Estimating the average impact of the reform in this subsample, we find that impact of the reform remained virtually unchanged, 1.52 percentage points compared to 1.53 . We then divide the sample into two groups based on whether the hospital had below- or above-median levels of uninsurance in the Before period. Among Massachusetts hospitals in the sample in the Before period, 29 hospitals had 
uninsurance below the national median, and the remaining 11 hospitals had uninsurance above the national median. We are able to estimate statistically significant impacts on uninsurance in both groups of hospitals, but estimates based on hospitals with below-median uninsurance are more precise.

Estimates from the first column of the third and fourth panels show that the impact of the reform was statistically indistinguishable in hospitals with lower initial rates of uninsurance (a 1.78 percentage point increase in coverage) and hospitals with higher initial rates of uninsurance (a 1.65 percentage point increase in coverage). Although we might have expected that convex cost of coverage expansion would have led to greater reductions in uninsurance in hospitals with initially higher rates of uninsurance, the results are not statistically different from each other. As shown in the second to fourth columns, impacts on length of stay and admissions from the ER were also similar across both groups of hospitals. Without recovering the structural parameters that determine the cost of coverage expansion it is difficult to make precise out of sample predictions. However, these findings suggest the results we find in Massachusetts, which had lower initial uninsurance than other states, could be similar to the impact of the national reform.

\section{Appendix C. Risk Adjustment}

Selection into hospitals after the reform in Massachusetts is an outcome of interest in its own right, which we address as a complement to our analysis, but to examine causal changes in other outcomes, we control for characteristics of the patient pool. To do so, we use $\operatorname{six}^{24}$ sets of risk adjustment variables: demographic characteristics, the number of diagnoses on the discharge record, individual components of the Charlson Score measure of comorbidities, AHRQ comorbidity measures, All-Patient Refined Diagnosis Related Groups (APR-DRGs), and All-Payer Severity-adjusted (APS-DRGs). Each risk adjustment measure was developed with a slightly different purpose, but the correlation among them is high. Since our focus is on controlling for selection and not on investigating the relative merit of each measure, we include all risk adjustment variables in the same specification. We run all of our regressions on the discharge level, as opposed to the hospital level, to capture the interactions between measures on the discharge level.

We construct the first four measures ourselves from the information in the discharge records. First, we include the same demographic measures that we include in specification 3 of Table 1 - saturated controls in race, gender, and income, as well as age and age squared. Second, following Gruber and Kleiner (2010), we control for the number of diagnoses on the hospital discharge record. The number of diagnoses in our nonelderly sample varies from 0 to 15 , the average is 5 , and the maximum potentially reported is 15 . Third, using data on the composition of diagnoses, we calculate and control for the individual components of the Charlson Score. ${ }^{25}$ The Charlson score, which includes 18 components, has been shown to have a strong relationship with mortality (Quan et al. (2005)). The average number of components in our nonelderly data is 0.37 , and the maximum is 9 . Fourth, we control for the 29 AHRQ comorbidity measures. The nonelderly mean in our data is 1 and the maximum is 14.

The remaining two measures were constructed in our data using proprietary algorithms. The APR-DRG measures and the APS-DRG measures, developed by 3M, were developed as

\footnotetext{
${ }^{24}$ In Kolstad and Kowalski (2010), we included a seventh set of risk adjusters, Medstat disease staging measures, but we must omit them here because they are no longer available in 2008.

${ }^{25}$ See Charlson et al. (1987) for the origin of the Charlson Score measures. We draw our Charlson Score code from http:// healthservices.cancer.gov/seermedicare/program/charlson.comorbidity.macro.txt.
} 
refinements to the existing Refined DRGs (R-DRGs) and All-Patient DRGs (AP-DRGs) systems, which expanded the DRG system beyond the Medicare population. The APR-DRG and APS-DRG measures include further adjustments for severity and for neonatal discharges. There are two separate APR-DRG measures: a mortality-specific measure and a general severity measure. We include both measures in each specification. The mortality measure takes on integer values from 0 to 4 with a mean in our data of 1.3 , and the severity measure takes on the same values with a mean of 1.7 .

There are three APS-DRG measures: one charge-specific measure, one length of stayspecific measure, and one mortality-specific measure. Each outcome-specific APS-DRG measure was developed using the 2000 NIS data, and is standardized to have a mean of 1 in that sample (HSS, Inc. (2003)). Multiplying the outcome-specific measure by the mean of that outcome in the 2000 NIS gives a prediction of the expected value of that outcome. For example, the mean charge in the 2000 NIS was $\$ 13,241.41$, and the largest value of the charge-specific APS-DRG for a discharge in our nonelderly sample was 26.21, so predicted charges for that discharge would be $\$ 347,057$ in the year 2000 . To interpret the other magnitudes, the mean LOS in the 2000 NIS was 4.5096, and mean mortality in the 2000 NIS was 0.0247 deaths per discharge. In our sample including all ages, the means of each measure are slightly greater than the standardized value of 1.0 , reffecting real changes in since the year 2000 and sampling changes from the 2000 NIS to 2004-2007 NIS. The charges measure takes on values from 0.09 to 26.21 , with a mean of 0.88 in the nonelderly sample; the length of stay measure takes on values from 0.21 to 19.02 , with a mean of 0.93 in the nonelderly sample; and the mortality measure takes on values from 0 to 46.74 , with a mean of 0.69 in the nonelderly sample. We include all three measures in each specification. The second specification of Appendix Table A3 reports the coefficients on all risk adjustment variables in the risk-adjusted uninsurance regression reported in the last row of the first specification in Table 1.

\section{Appendix D. Prevention Quality Indicators}

We use software from AHRQ to calculate these measures in our NIS data (Agency for Healthcare Research and Quality 2007a)). We use the December 2009 Version 4.1 of the Prevention Quality Indicators (Agency for Healthcare Research and Quality (2007b)), the most recent version that does not include a windows executable file. The calculation of each one of these quality indicators is often based on a complicated algorithm because the diagnosis first needs to be identified, and then specific discharges must be excluded based on secondary diagnoses and risk factors that mitigate the potential for prevention. Each quality measure includes a numerator, a specific condition, and a denominator, the population at risk for this specific condition, which sometimes represents the entire population in a geographic area. The presence of the numerator and denominator allows a researcher to calculate rates with data for a single hospital. Since our research design compares hospitals to each other and to themselves over time, we do not calculate any of the measures as rates. Instead, we use a dummy dependent variable to indicate inclusion in the numerator - the presence of a quality measure on a specific discharge. For each quality measure, we restrict the sample to discharges included in the denominator.

\section{Appendix E. Behavioral Risk Factor Surveillance System (BRFSS)}

The BRFSS is a cross-sectional telephone survey conducted by state health departments on a monthly basis with technical and methodological assistance provided by the Centers for Disease Control (CDC). Sampling follows a multistage design based on random-digitdialing in order to select a representative sample from the non-institutionalized adult population in each state and territory. Our sample from BRFSS data contain 2,293,672 
observations; in the analysis, data are weighted for the probability of selection of a telephone number, the number of adults in a household, and the number of telephones in a household; post-stratification adjustments are also made for non-response and non-coverage of households without telephones.

\section{Appendix F. Comparison of NIS Hospital Sample to the Universe of Hospitals in Massachusetts}

One important question in evaluating our results is the degree to which the NIS hospital sample is reffective of the actual distribution of hospitals in Massachusetts. To address this issue, we obtained the detailed data on the universe of hospitals in the state of Massachusetts from the Massachusetts Department of Health Care Finance and Policy. Appendix Table A6 presents a comparison of the hospitals in the two samples in 2008, the most recent year of our data. The comparison of means across the two samples demonstrates clearly the similarities between the two. The NIS sample appears to have more large hospitals than the universe though the average number of beds is relatively similar. The composition by forprofit and not-for-profit status in the NIS appears to be highly representative of the universe of discharges, as are most of the variables. This comparison makes clear that while the NIS is a sample intended to be nationally representative, in Massachusetts, the discharges included in the NIS are very reffective of the universe of discharges in our sample period. 


\section{Highlights}

- Massachusetts passed health reform legislation in April 2006.

- We compare outcomes in Massachusetts and other states before and after the reform.

- Among hospital discharges, the reform decreased uninsurance by $36 \%$.

- Length of stay and inpatient admissions from the emergency room decreased.

- Hospital cost growth did not increase. 


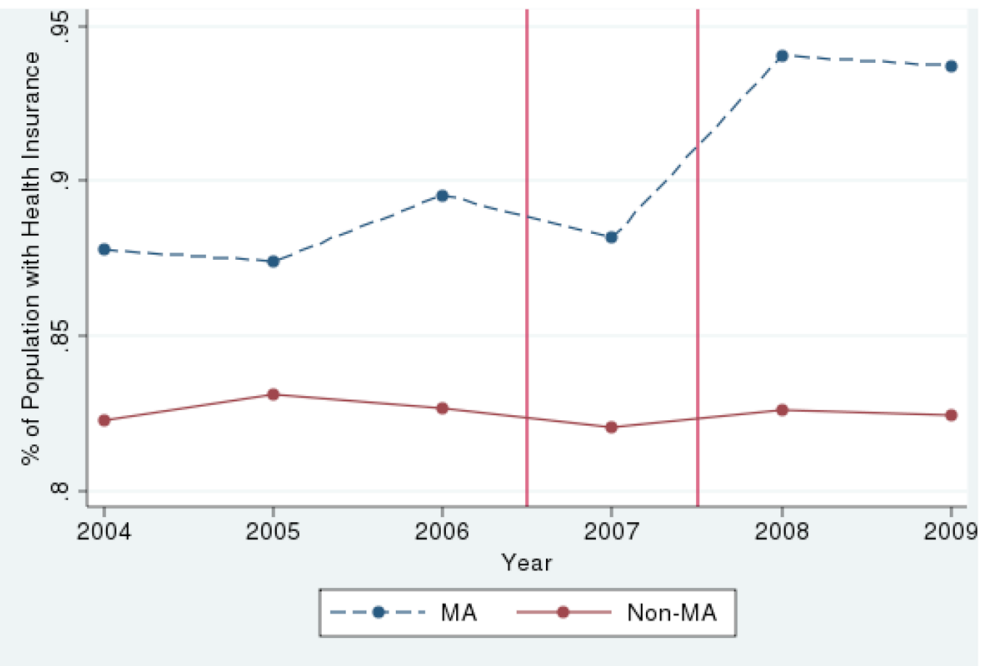

Figure 1.

Mean Coverage Rates by Year

Source: 2004-2009 Supplements to the Current Population Survey, authors' calculations. Vertical lines separate During and After periods. 

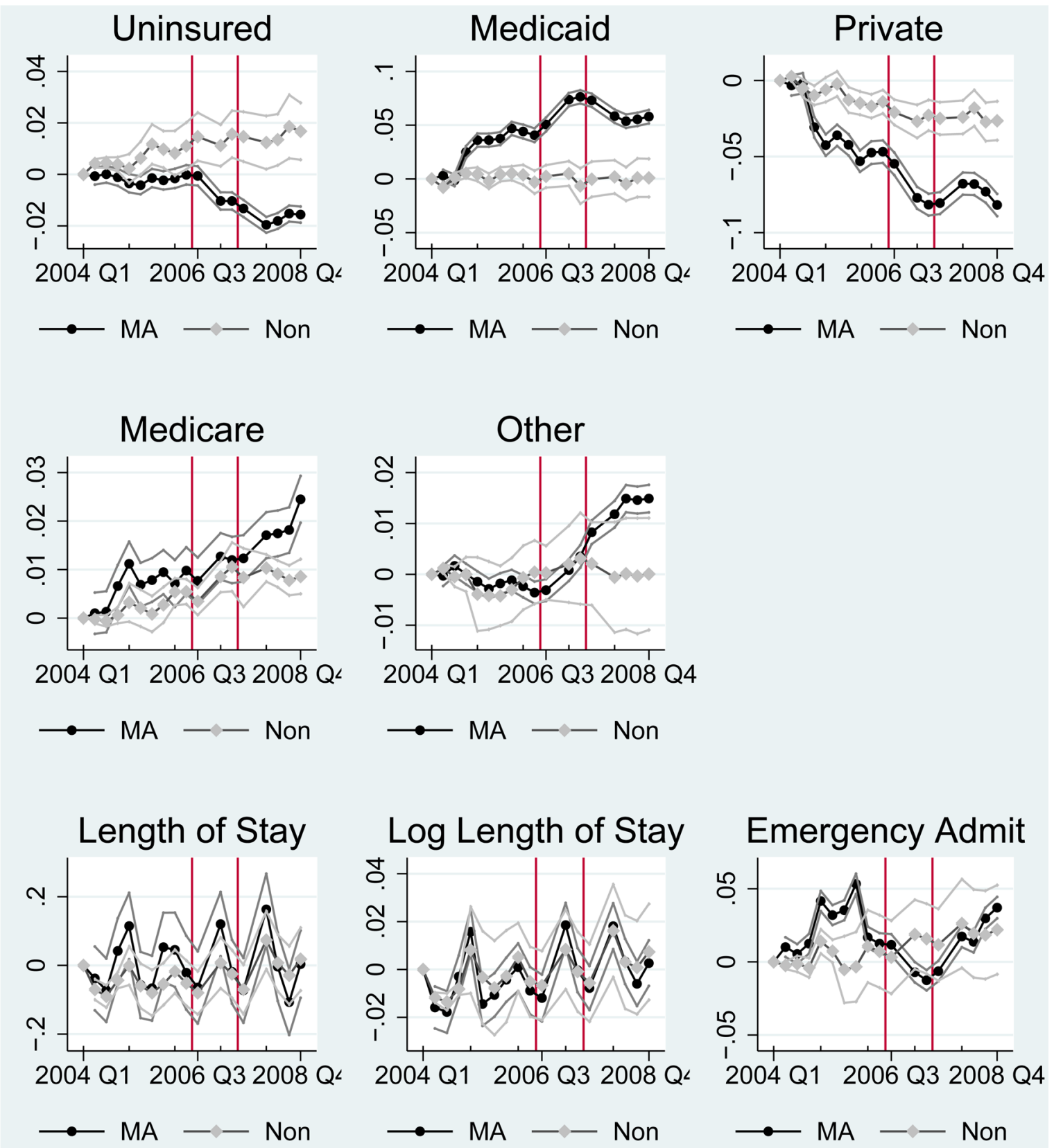

Figure 2.

Trends in MA vs. Non-MA

Source: NIS authors' calculations.

Trends obtained from regressions including hospital fixed effects.

95\% asympototic confidence intervals shown.

Confidence intervals clustered by state for Non-MA and robust for MA.

All data omitted in 2006 Q4 and 2007 Q4 because of MA data availability.

Vertical lines separate During and After periods. 

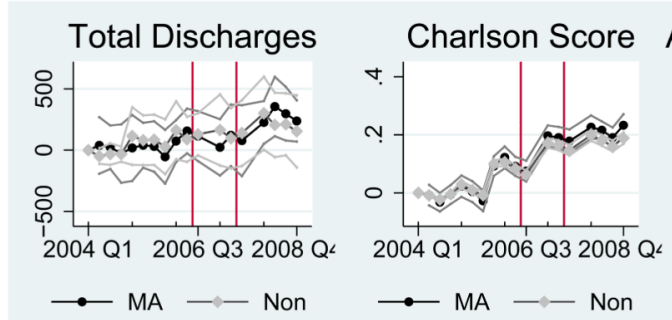

APRDRG Risk Mortality

APRDRG Severity

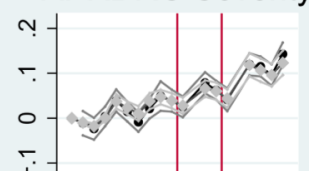

2004 Q1 2006 Q3 2008 Q،

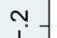

APSDRG Mort. Wei. APSDRG LOS Weight

$\because$ MA - Non
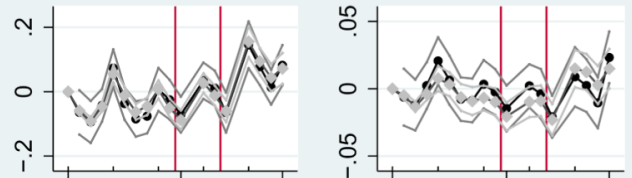

\&.

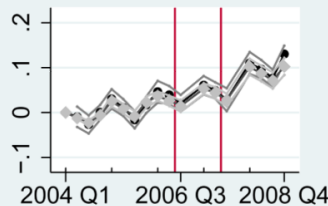

$\longrightarrow$ MA $\longrightarrow$ Non

$\longrightarrow$ MA $\longrightarrow$ Non

$\longrightarrow$ MA $\longrightarrow$ Non

APSDRG Charge Weight

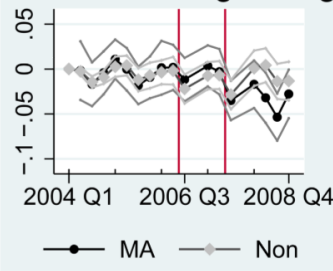

Figure 3.

Trends in MA vs. Non-MA, Hospital Quarter Level

Source: NIS authors' calculations.

Trends obtained from regressions including hospital fixed effects.

95\% asympototic confidence intervals shown.

Confidence intervals clustered by state for Non-MA and robust for MA.

All data omitted in 2006 Q4 and 2007 Q4 because of MA data availability.

Vertical lines separate During and After periods. 

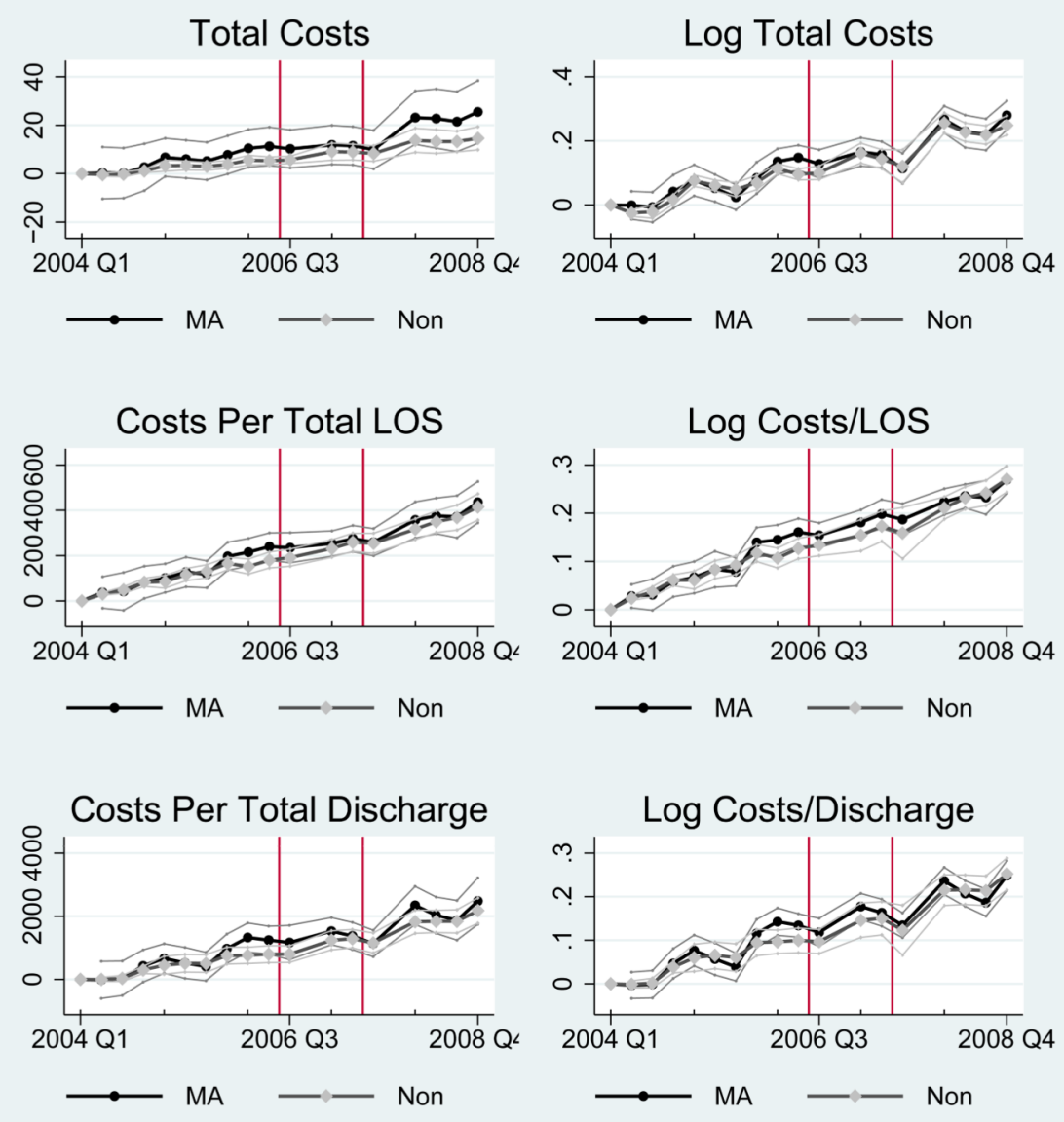

Figure 4.

Trends in MA vs. Non-MA, Hospital Quarter Level

Source: NIS authors' calculations.

Trends obtained from regressions including hospital fixed effects.

95\% asympototic confidence intervals shown.

Confidence intervals clustered by state for Non-MA and robust for MA.

All data omitted in 2006 Q4 and 2007 Q4 because of MA data availability.

Vertical lines separate During and After periods. 


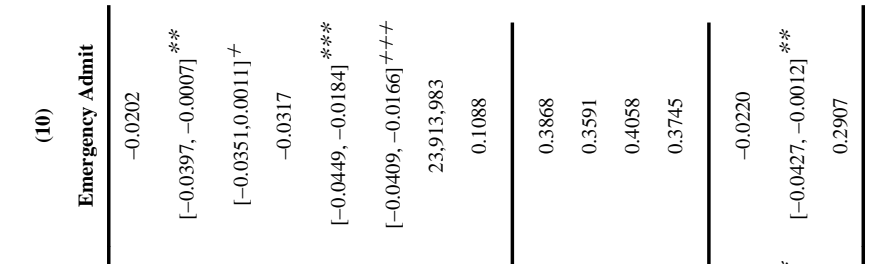

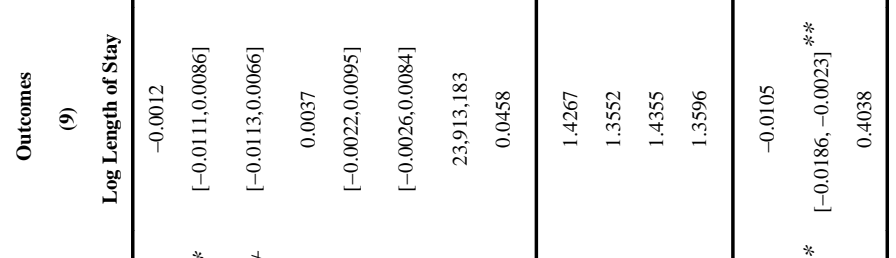

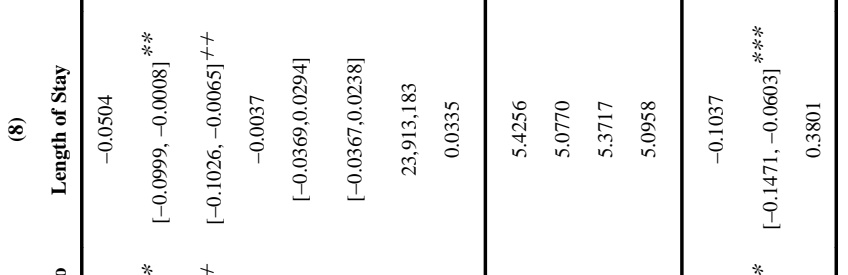

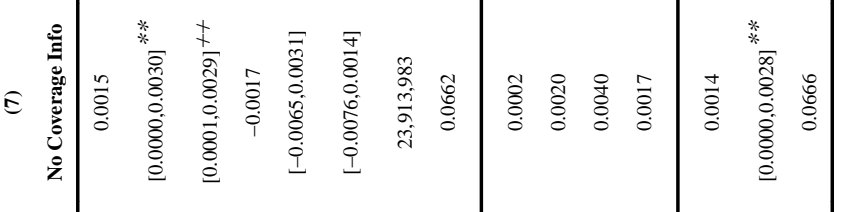

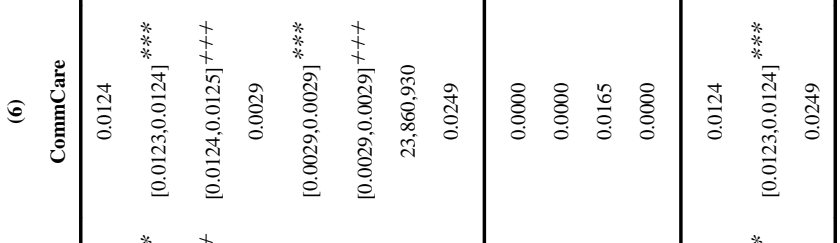

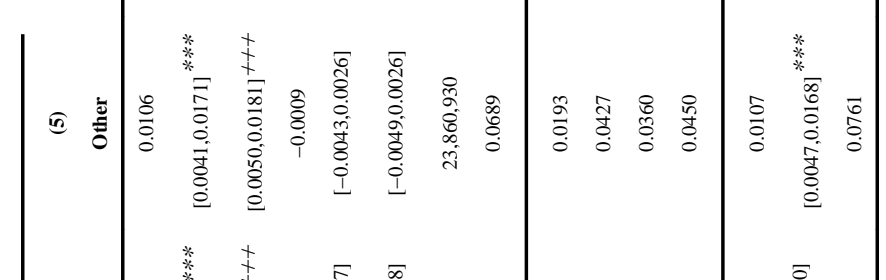

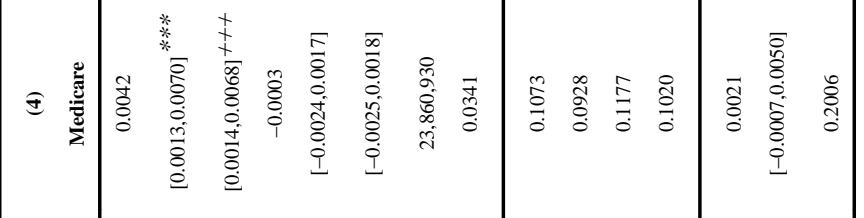

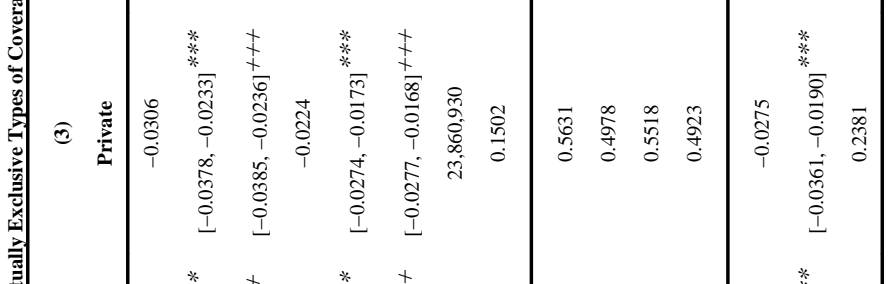

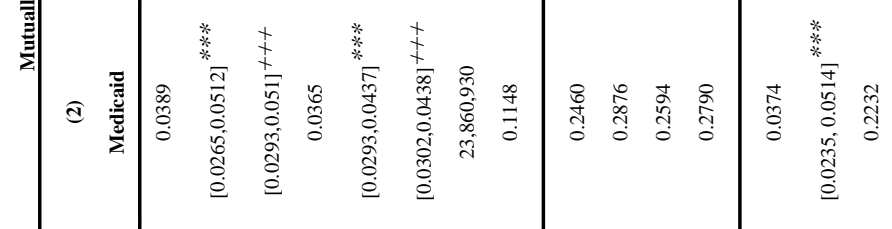

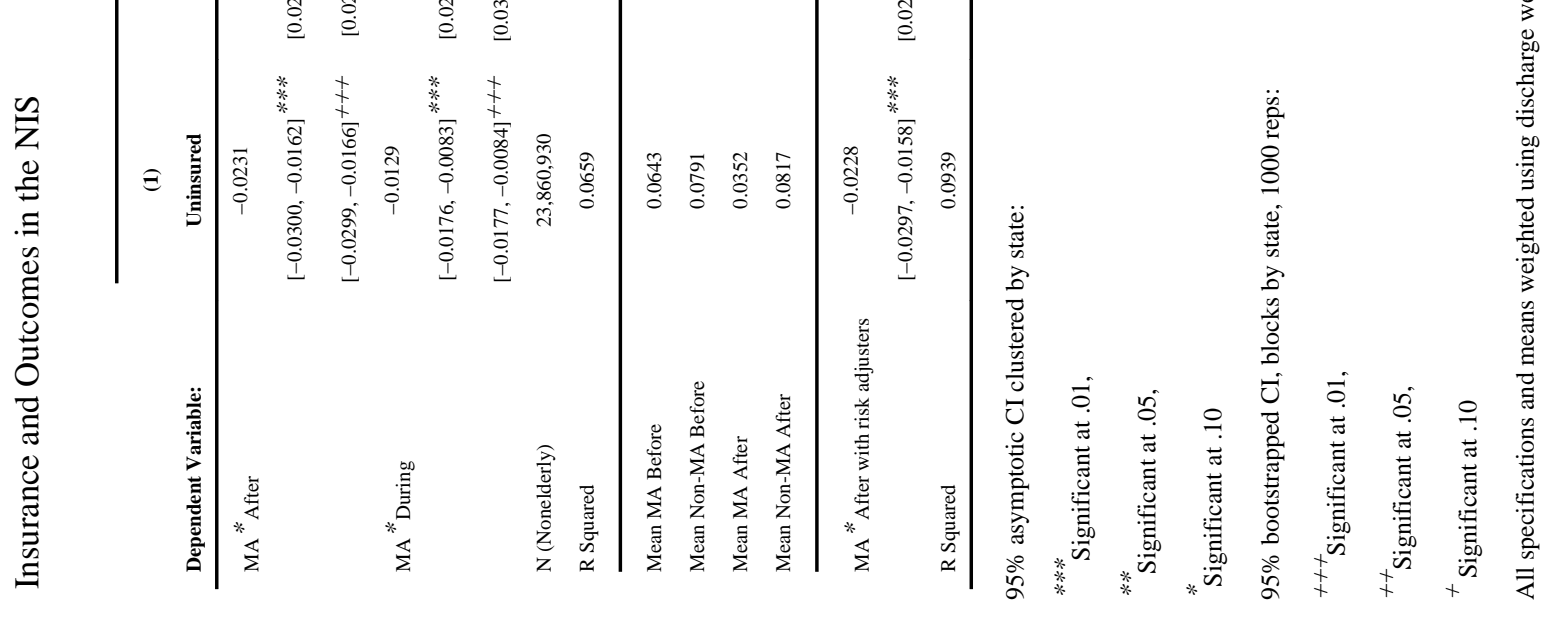




$$
\|
$$




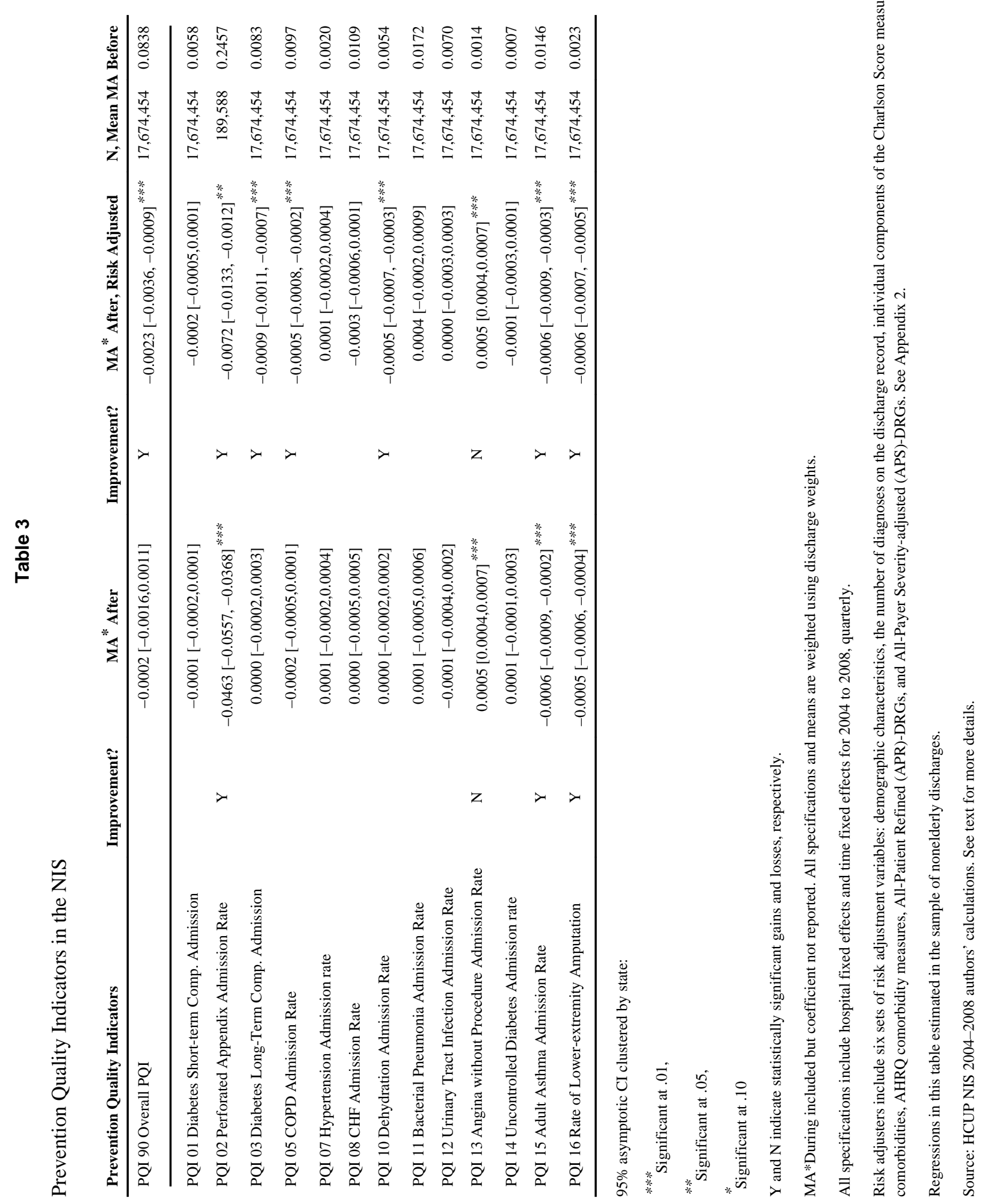




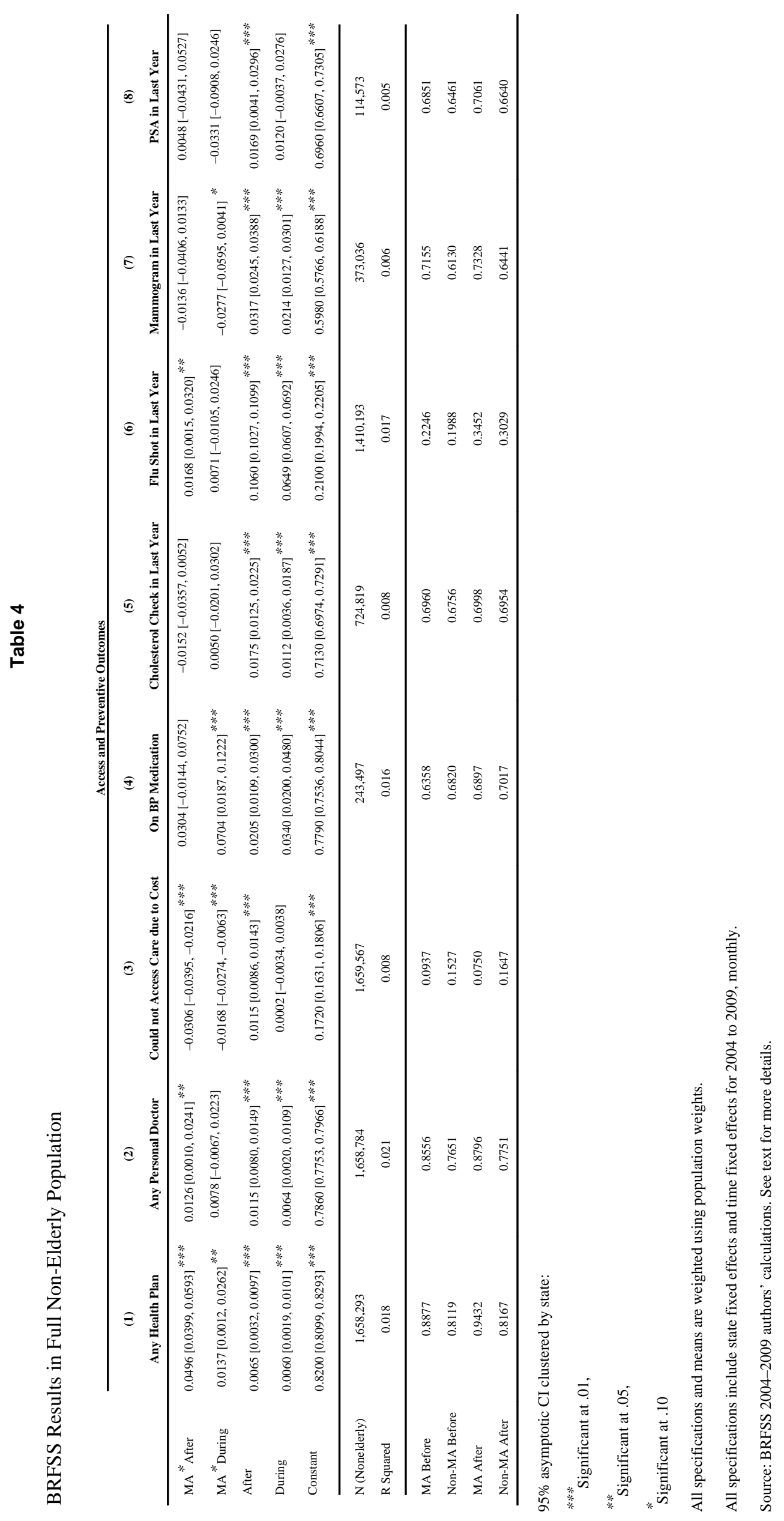

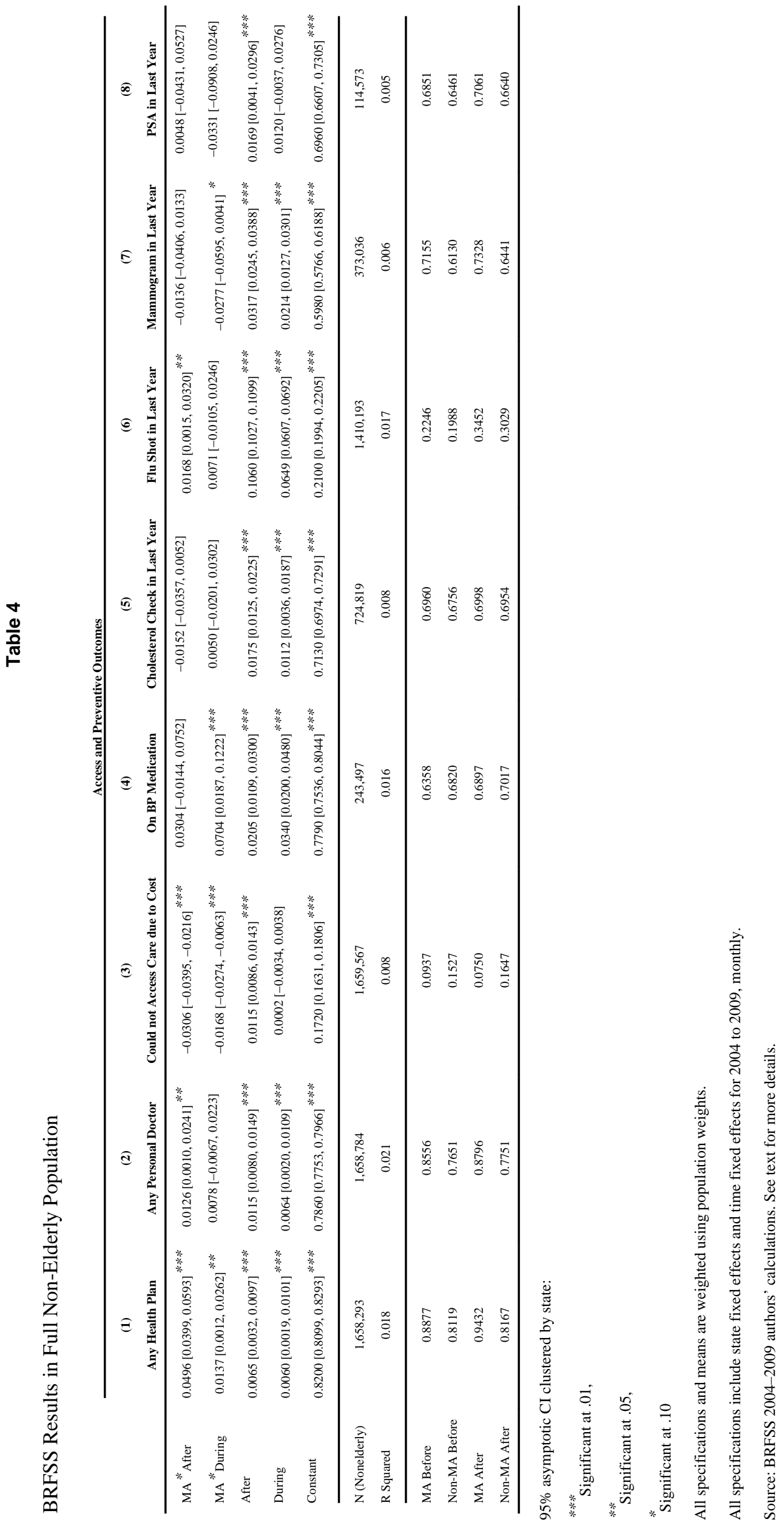




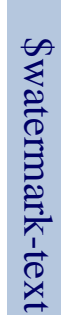

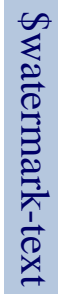

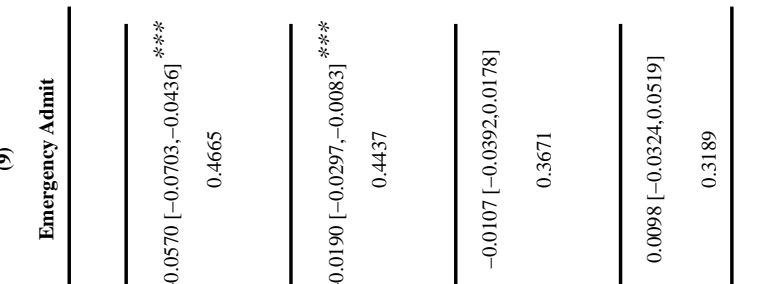

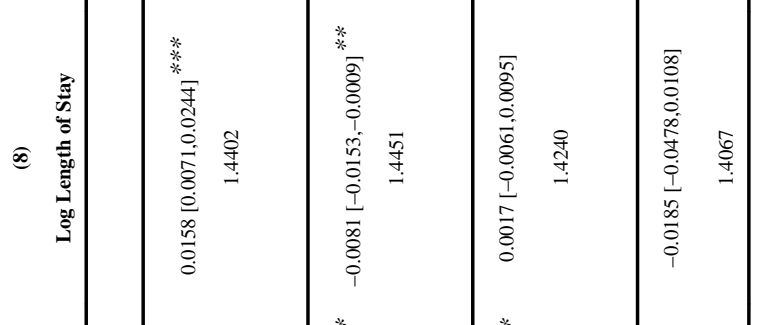

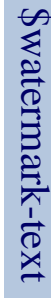

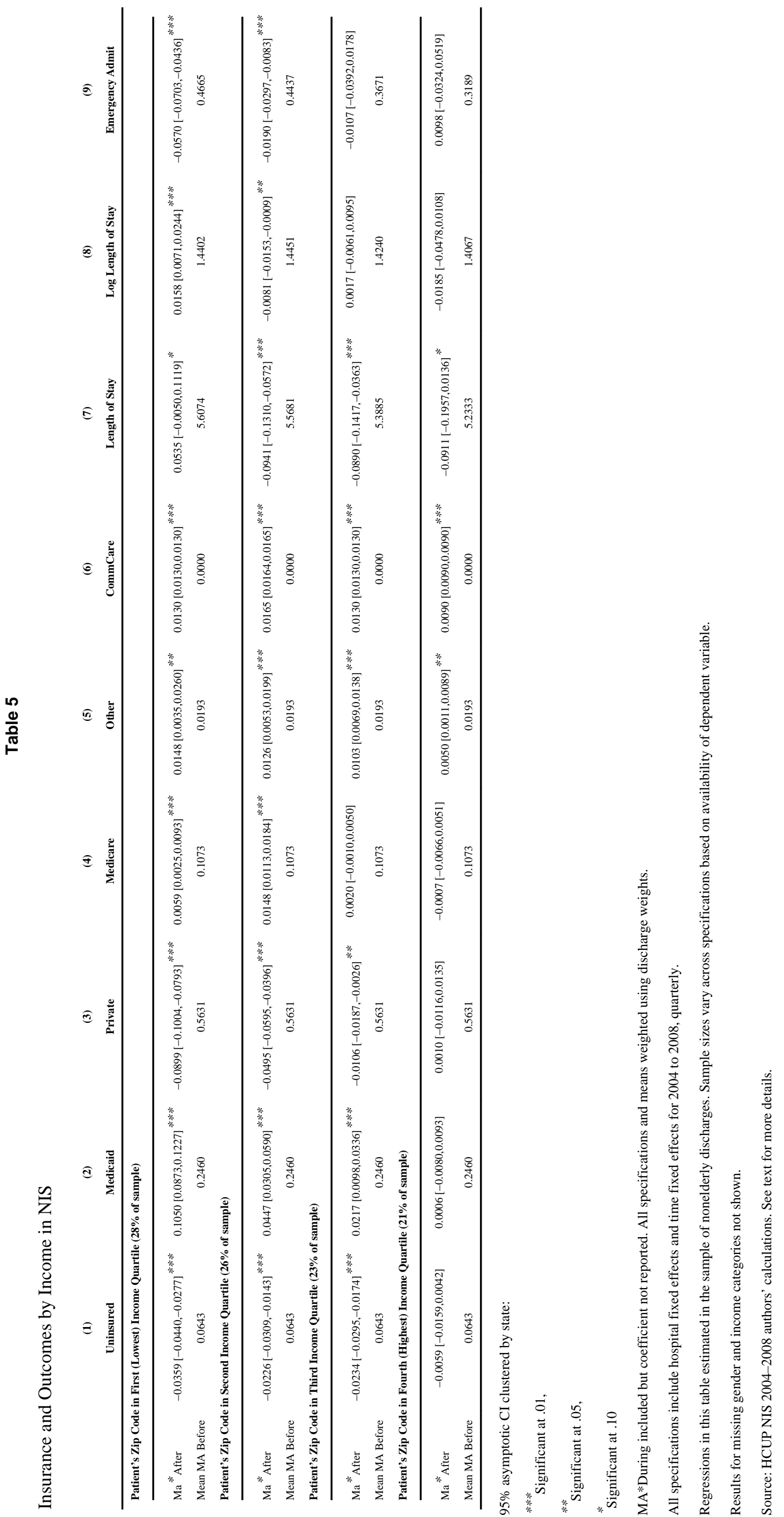




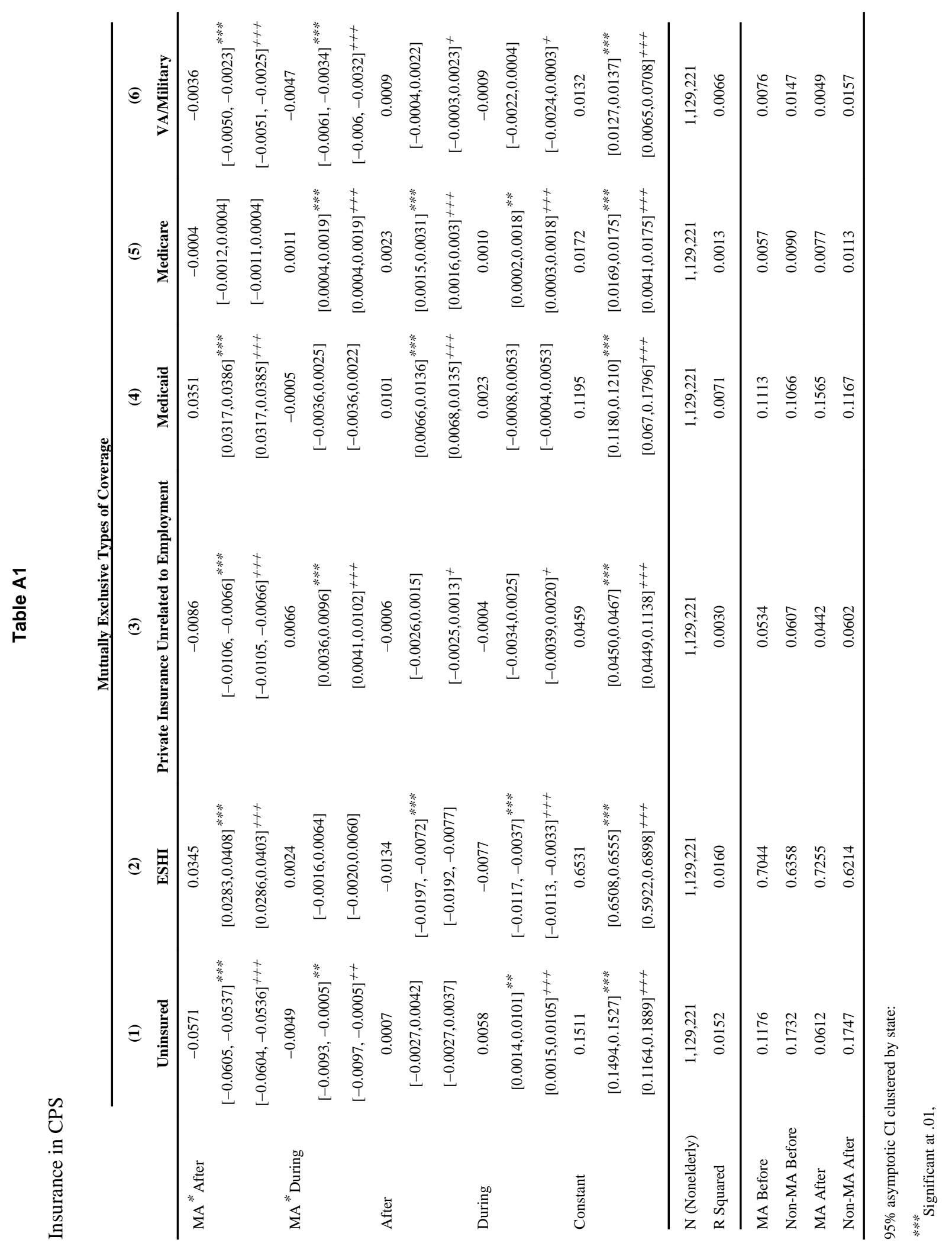




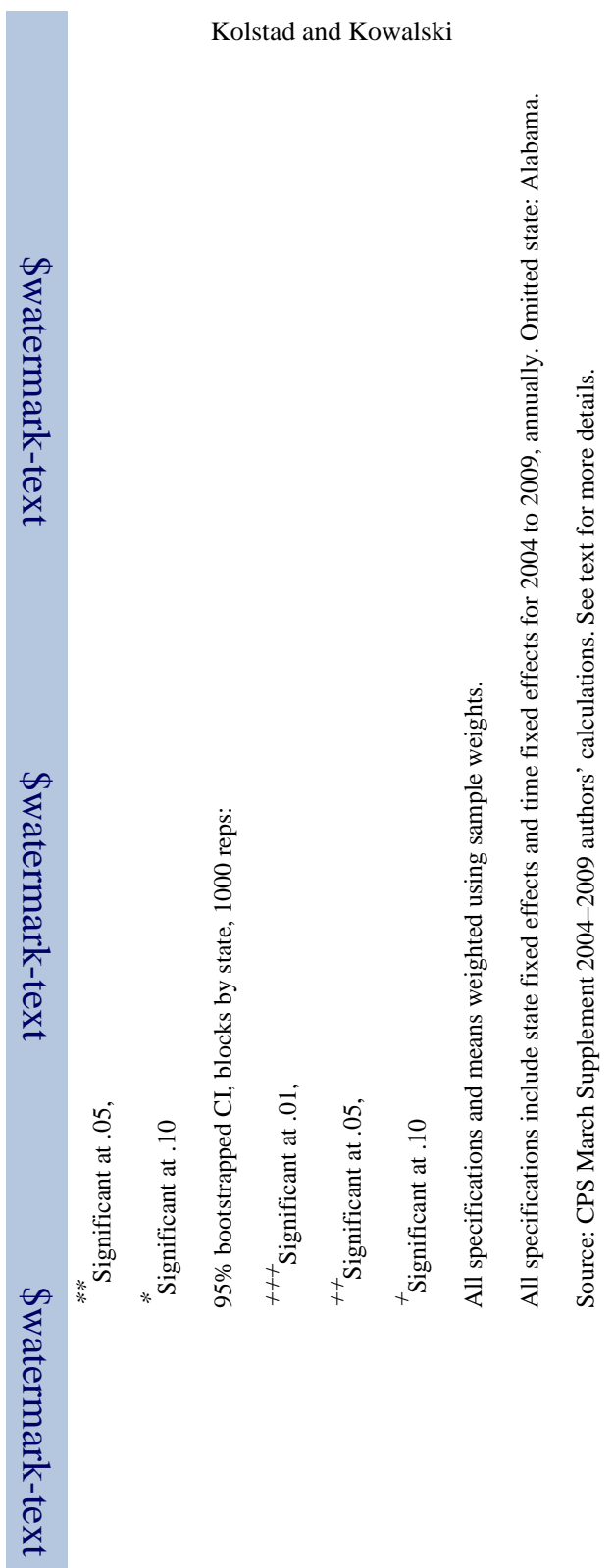

J Public Econ. Author manuscript; available in PMC 2013 December 01. 

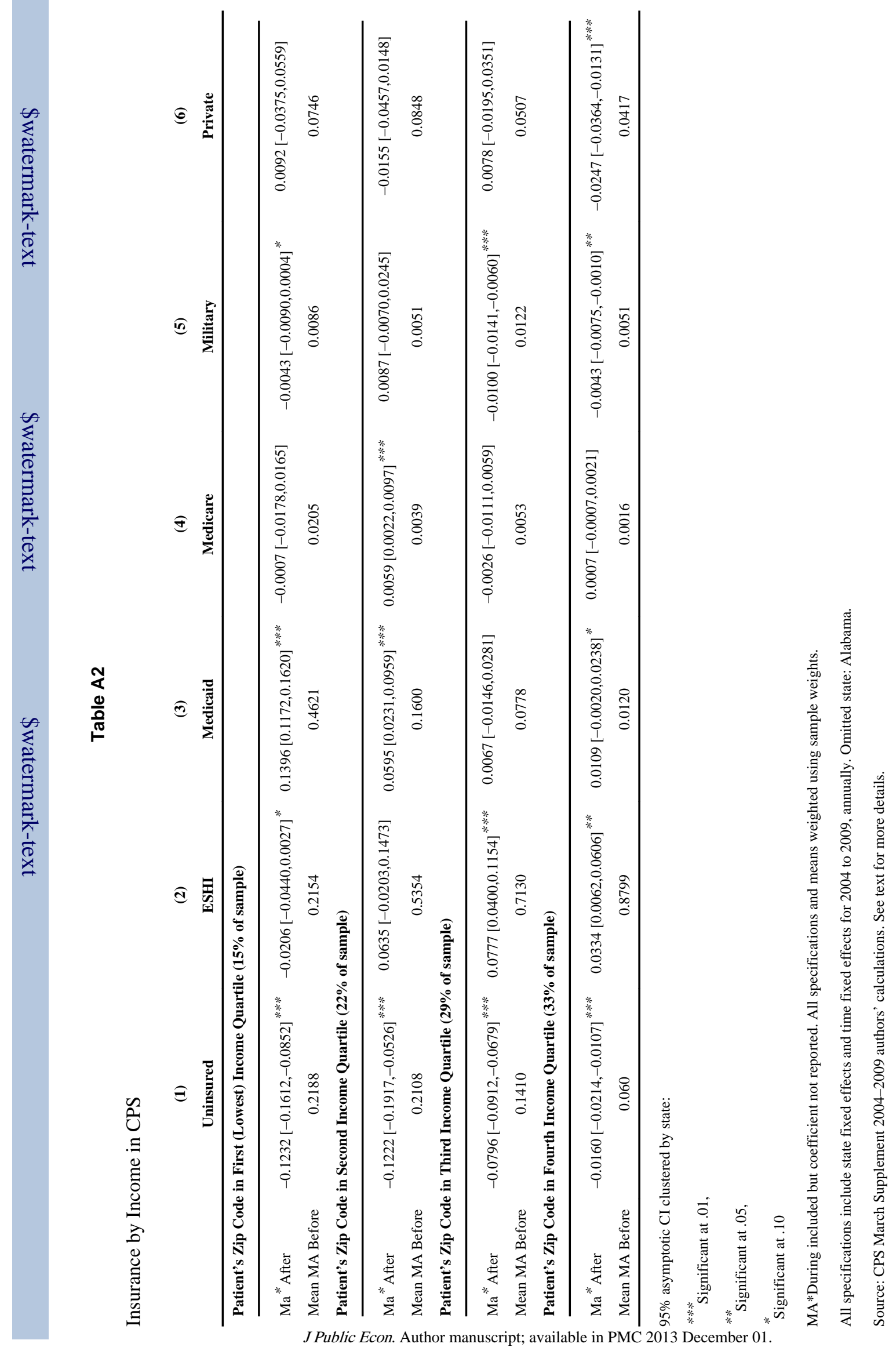


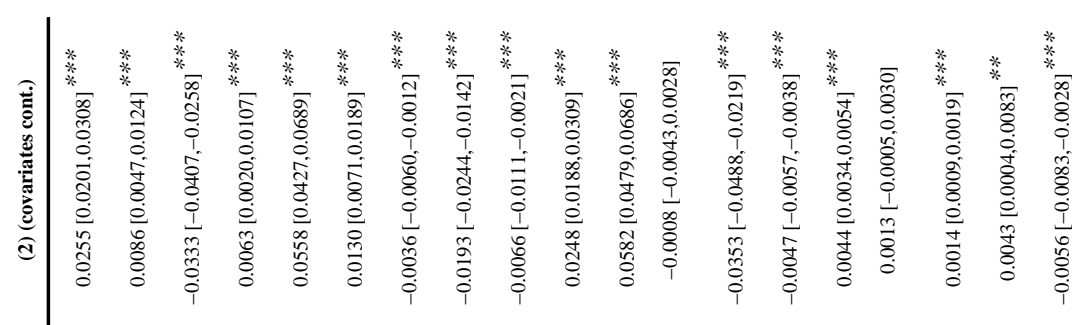

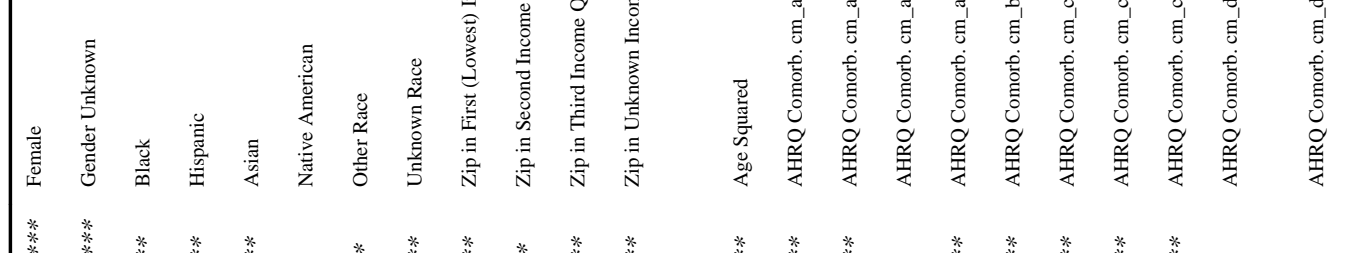




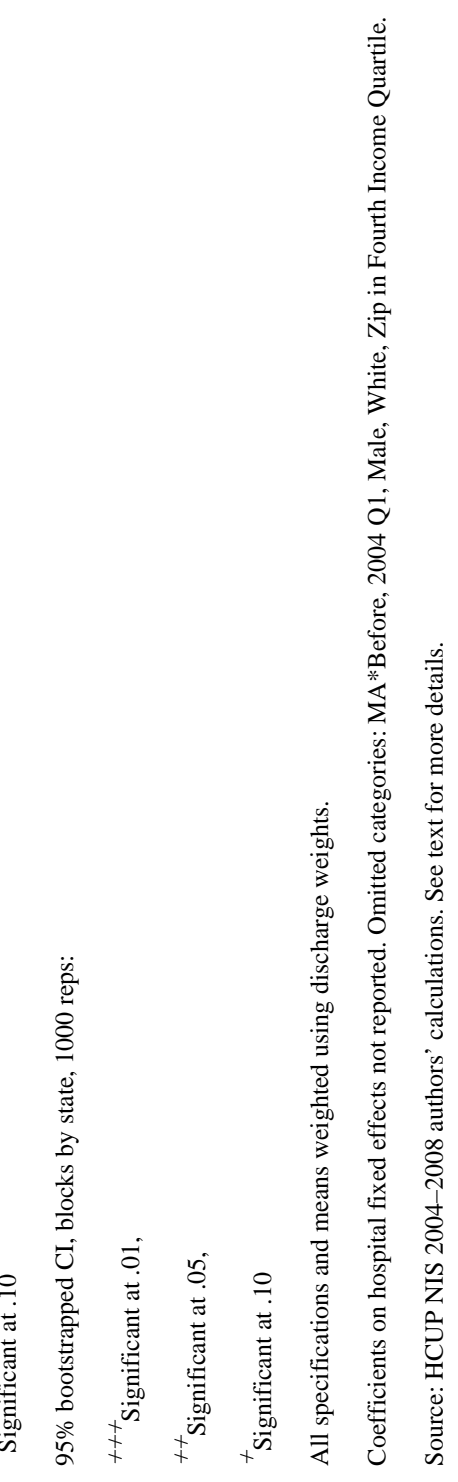


Table A4

Robustness to Included States in NIS

(1)

Uninsured
(2)

Length of Stay
(3)

(4)

\begin{tabular}{|c|c|c|c|c|}
\hline & Uninsured & Length of Stay & Log Length of Stay & Emergency Admit \\
\hline \multicolumn{5}{|l|}{ All States } \\
\hline MA ${ }^{*}$ After & $-0.0231[-0.0300,-0.0162]^{* * *}$ & $-0.0504[-0.0999,-0.0008]^{* *}$ & $-0.0012[-0.0111,0.0086]$ & $-0.0202[-0.0397,-0.0007]^{* *}$ \\
\hline N (Nonelderly) & $23,860,930$ & $23,913,183$ & $23,913,183$ & $23,913,983$ \\
\hline Mean MA Before & 0.0643 & 5.4256 & 1.4267 & 0.3868 \\
\hline Mean MA After & 0.0352 & 5.3717 & 1.4355 & 0.4058 \\
\hline Mean Non-MA After & 0.0817 & 5.0958 & 1.3596 & 0.3745 \\
\hline \multicolumn{5}{|l|}{ Northeast } \\
\hline MA ${ }^{*}$ After & $-0.0160[-0.0309,-0.0011]^{* *}$ & $-0.0293[-0.2007,0.1421]$ & $-0.0070[-0.0551,0.0411]$ & $-0.0293[-0.0500,-0.0085]^{* *}$ \\
\hline Mean Non-MA Before & 0.0790 & 5.6529 & 1.4163 & 0.4281 \\
\hline Mean Non-MA After & 0.0613 & 5.6453 & 1.4203 & 0.4425 \\
\hline \multicolumn{5}{|l|}{ New England } \\
\hline MA ${ }^{*}$ After & $-0.0159[-0.0193,-0.0125]^{* * *}$ & $-0.0021[-0.1276,0.1233]$ & $0.0170[-0.0214,0.0554]$ & $-0.0411[-0.0749,-0.0072]^{* *}$ \\
\hline N (Nonelderly) & $1,369,181$ & $1,370,420$ & $1,370,420$ & $1,370,438$ \\
\hline Mean Non-MA Before & 0.0450 & 5.3462 & 1.3890 & 0.3337 \\
\hline Mean Non-MA After & 0.0408 & 5.3576 & 1.3840 & 0.3324 \\
\hline \multicolumn{5}{|l|}{ All, No ME, VT, CA } \\
\hline $\mathrm{MA}^{*}$ After & $-0.0236[-0.0311,-0.0161]^{* * *}$ & $-0.0537[-0.1082,0.0008]^{*}$ & $-0.0022[-0.0129,0.0085]$ & $-0.0202[-0.0417,0.0013]^{*}$ \\
\hline Mean Non-MA Before & 0.0837 & 5.0926 & 1.3606 & 0.3653 \\
\hline Mean Non-MA After & 0.0871 & 5.0996 & 1.3644 & 0.3813 \\
\hline \multicolumn{5}{|l|}{25 Most Insured } \\
\hline $\mathrm{MA}^{*}$ After & $-0.0246[-0.0367,-0.0126]^{* * *}$ & $-0.0477[-0.0817,-0.0138]^{* * *}$ & $0.0056[-0.0012,0.0124]$ & $-0.0066[-0.0623,0.0491]$ \\
\hline N (Nonelderly) & $8,028,553$ & $8,057,249$ & $8,057,249$ & $8,057,439$ \\
\hline Mean Non-MA Before & 0.0595 & 4.9274 & 1.3424 & 0.3300 \\
\hline Mean Non-MA After & 0.0638 & 4.9342 & 1.3438 & 0.3426 \\
\hline
\end{tabular}

Balanced Panel (Only Hospitals That Appear in Data in Every Possible Quarter)

\begin{tabular}{|c|c|c|c|c|}
\hline MA ${ }^{*}$ After & $-0.0273[-0.0500,-0.0045]^{* *}$ & $0.1087[-0.0872,0.3045]$ & $0.0297[-0.0038,0.0633]^{*}$ & $0.0244[-0.0705,0.1193]$ \\
\hline $\mathrm{N}$ (Nonelderly) & 768,541 & 770,696 & 770,696 & 770,699 \\
\hline Mean MA Before & 0.0461 & 5.4089 & 1.4104 & 0.4701 \\
\hline Mean Non-MA Before & 0.0714 & 4.6790 & 1.3037 & 0.2769 \\
\hline Mean MA After & 0.0279 & 5.4701 & 1.4323 & 0.4902 \\
\hline Mean Non-MA After & 0.0800 & 4.6364 & 1.2969 & 0.2720 \\
\hline
\end{tabular}

J Public Econ. Author manuscript; available in PMC 2013 December 01. 
95\% asymptotic CI clustered by state:

****

Significant at .01,

**

Significant at .05 ,

* Significant at .10

MA*During included but coefficient not reported.

All specifications and means weighted using discharge weights.

All specifications include hospital fixed effects and time fixed effects for 2004 to 2008, quarterly.

“All States" sample includes all states in the 2004-2008 NIS. Does not include AL, AK, DE, ID, MS, MT, ND, NM.

“New England” sample includes MA, CT, NH, VT, ME, RI. "Northeast” sample includes New England, NY, NJ.

"25 Most Insured" includes the top half of states in terms of initial levels of insurance from the CPS.

In decreasing order of insurance, "25 Most Insured" includes: MN, HI, IA, NH, ME, WI, MA, VT, KS, RI, NE, MI, ND (not in NIS), CT, PA, OH, M0, SD, DE (not in NIS), VA, MD, TN, KY, UT.

"Balanced Panel" only includes states that appear in every possible quarter of the data. These hospitals are in AZ (2), CA, CO (2), GA, MA (2), MD, MN, NC, NE, OH, TN, TX (4), UT, WA (4), WV (2).

Source: HCUP NIS 2004-2008 authors' calculations. See text for more details. 
Table A5

Insurance and Outcomes in Low vs. High Uninsured Hospitals in NIS

(1)

Uninsured
(2)

Length of Stay

(3)

Log Length of Stay

(4)

Emergency Admit

\begin{tabular}{lcccc}
\hline All Hospitals (100\% of sample, including missing ages) & & & \\
\hline Ma ${ }^{*}$ After & $-0.0153[-0.0201,-0.0104]^{* * *}$ & $-0.0626[-0.1102,-0.0150]^{* *}$ & $0.0006[-0.0090,0.0103]$ & $-0.0367[-0.0585,-0.0149]^{* * * *}$ \\
N (All Ages) & $36,282,073$ & $36,343,449$ & $36,343,449$ & $36,345,238$ \\
N Hospitals & 3,090 & 3,090 & 3,090 & 3,090 \\
N Hospitals in MA & 48 & 48 & 48 & 48 \\
\hline Mean MA Before & 0.0409 & 5.8833 & 1.5099 & 0.4789 \\
Mean Non-MA Before & 0.0543 & 5.6256 & 1.4517 & 0.4291 \\
Mean MA After & 0.0226 & 5.7516 & 1.5084 & 0.4912 \\
Mean Non-MA After & 0.0557 & 5.5819 & 1.4482 & 0.4491
\end{tabular}

Only Hospitals that Appear in Data At Least Once Before Reform

\begin{tabular}{|c|c|c|c|c|}
\hline $\mathrm{Ma}^{*}$ After & $-0.0152[-0.0202,-0.0102]^{* * * *}$ & $-0.0651[-0.1155,-0.0147]^{* *}$ & $-0.0001[-0.0104,0.0102]$ & $-0.0369[-0.0596,-0.0143]^{* * * *}$ \\
\hline N (All Ages) & $30,390,240$ & $30,441,321$ & $30,441,321$ & $30,442,760$ \\
\hline N Hospitals & 2,315 & 2,315 & 2,315 & 2,315 \\
\hline $\mathrm{N}$ Hospitals in MA & 40 & 40 & 40 & 40 \\
\hline Mean MA Before & 0.0409 & 5.8833 & 1.5099 & 0.4789 \\
\hline Mean Non-MA Before & 0.0543 & 5.6256 & 1.4517 & 0.4291 \\
\hline Mean MA After & 0.0230 & 5.7678 & 1.5085 & 0.4856 \\
\hline Mean Non-MA After & 0.0595 & 5.5803 & 1.4460 & 0.4473 \\
\hline
\end{tabular}

Low Uninsured Hospitals

\begin{tabular}{|c|c|c|c|c|}
\hline $\mathrm{Ma}^{*}$ After & $-0.0178[-0.0228,-0.0129]^{* * *}$ & $-0.0895[-0.1522,-0.0269]^{* * *}$ & $0.0019[-0.0074,0.0112]$ & $-0.0409[-0.0577,-0.0241]^{* * * *}$ \\
\hline N (All Ages) & $14,407,631$ & $14,426,624$ & $14,426,624$ & $14,427,194$ \\
\hline N Hospitals & 1,157 & 1,157 & 1,157 & 1,157 \\
\hline $\mathrm{N}$ Hospitals in MA & 29 & 29 & 29 & 29 \\
\hline Mean MA Before & 0.0303 & 5.8769 & 1.5058 & 0.4431 \\
\hline Mean Non-MA Before & 0.0210 & 5.6142 & 1.4487 & 0.4087 \\
\hline Mean MA After & 0.0220 & 5.7938 & 1.5119 & 0.4742 \\
\hline Mean Non-MA After & 0.0295 & 5.6036 & 1.4438 & 0.4306 \\
\hline
\end{tabular}

\section{High Uninsured Hospitals}

\begin{tabular}{|c|c|c|c|c|}
\hline $\mathrm{Ma}^{*}$ After & $-0.0165[-0.0246,-0.0085]^{* * *}$ & $-0.0260[-0.0782,0.0263]$ & $-0.0063[-0.0151,0.0024]$ & $-0.0086[-0.0312,0.0140]$ \\
\hline N (All Ages) & $15,982,609$ & $16,015,279$ & $16,015,279$ & $16,016,149$ \\
\hline N Hospitals & 1,158 & 1,158 & 1,158 & 1,158 \\
\hline $\mathrm{N}$ Hospitals in MA & 11 & 11 & 11 & 11 \\
\hline
\end{tabular}

J Public Econ. Author manuscript; available in PMC 2013 December 01. 
(1)

Uninsured

\begin{tabular}{l}
\hline Mean MA Before \\
Mean Non-MA Before \\
Mean MA After \\
Mean Non-MA After \\
\hline $95 \%$ asymptotic CI clustered by state: \\
S*** Significant at .01, \\
Significant at .05, \\
S Significant at .10
\end{tabular}

MA*During included but coefficient not reported

All specifications and means weighted using discharge weights.

All specifications include hospital fixed effects and time fixed effects for 2004 to 2008, quarterly.

Low Uninsured Hospitals have less than median uninsurance of 0.0398 before reform.

Sample sizes vary across specifications based on availability of dependent variable.

Source: HCUP NIS 2004-2008 authors' calculations. See text for more details.
(3)

(4)

Length of Stay

Log Length of Stay

1.5186

1.4546

1.4808

1.4478
Emergency Admit

0.5550

0.4478

0.5769

0.4612 
Table A6

Comparison of Massachusetts Hospital Characteristics in the NIS HCUP and Casemix Datasets, AHA Data 2008

\begin{tabular}{|c|c|c|}
\hline & $\begin{array}{l}\text { Acute Care Hospitals (Casemix Dataset) } \\
\qquad[\mathrm{n}=64]\end{array}$ & NIS-HCUP Hospitals [n=15] \\
\hline \multicolumn{3}{|c|}{ Hospital Characteristics } \\
\hline$\%$ Teaching hospitals & 21.88 & 26.67 \\
\hline$\%$ Community hospitals & 98.44 & 100.00 \\
\hline$\%$ Short-term hospitals & 98.44 & 100.00 \\
\hline$\%$ Participant in a hospital network & 33.33 & 35.71 \\
\hline$\%$ DSH hospitals & 28.13 & 26.67 \\
\hline \multicolumn{3}{|l|}{$\underline{\text { Hospital ownership }}$} \\
\hline Government, Nonfederal: Hospital district or authority & 1.56 & 6.67 \\
\hline$\%$ Nongovernment, not-for-profit: Church operated & 7.81 & 0.00 \\
\hline$\%$ Nongovernment, not-for-profit: Other not-for-profit & 84.38 & 86.67 \\
\hline$\%$ Investor-owned (for-profit): Corporation & 6.25 & 6.67 \\
\hline$\%$ Government, federal: Veterans Affairs & 0.00 & 0.00 \\
\hline
\end{tabular}

Hospital Bed Size \& Admissions

\begin{tabular}{lcc}
\hline Average total hospital beds & 229.78 & 252.80 \\
\% Hospitals in each bed size category & & 0.00 \\
\hline 6 -24 beds & 4.69 & 13.33 \\
$25-49$ beds & 9.38 & 20.00 \\
$50-99$ beds & 14.06 & 26.67 \\
100-199 beds & 28.12 & 0.00 \\
$200-299$ beds & 15.62 & 20.00 \\
300-399 beds & 12.50 & 6.67 \\
$400-499$ beds & 4.69 & 13.33 \\
500 or more beds & 10.94 & $13,642.67$ \\
Average number of admissions & $12,074.88$ & $68,932.33$ \\
Average inpatient days & $61,987.61$ & $5,761.67$ \\
Average Medicare inpatient discharges & $5,231.20$ & $2,522.60$ \\
Average Medicaid inpatient discharges & $2,088.06$ & $51,384.67$ \\
Average number of mergency outpatient visits & $46,983.44$ & $327,945.30$ \\
Average number of total outpatient visits & $304,308.50$ & \\
\hline
\end{tabular}

Hospital Expenditures, Payment \& Employment

\begin{tabular}{lcc}
\hline Average payroll expenditures & $125,000,000$ & $137,000,000$ \\
Average total expenditures & $314,000,000$ & $357,000,000$ \\
$\%$ Net revenue paid on a capitated basis & 0.67 & 0.33 \\
$\%$ Net revenue paid on a shared risk basis & 3.85 & 2.56 \\
Average number of full-time physicians and dentists & 87.86 & 134.87
\end{tabular}


Acute Care Hospitals (Casemix Dataset) $[n=64]$

Average number of part-time physicians and dentists
NIS-HCUP Hospitals [n=15] 45.07 